\title{
Botanicals as Modulators of Neuroplasticity: Focus on BDNF
}

\author{
Enrico Sangiovanni, Paola Brivio, Mario Dell'Agli, and Francesca Calabrese \\ Department of Pharmacological and Biomolecular Sciences, Università degli Studi di Milano, Milan, Italy \\ Correspondence should be addressed to Francesca Calabrese; francesca.calabrese@unimi.it
}

Received 7 June 2017; Revised 9 November 2017; Accepted 2 December 2017; Published 31 December 2017

Academic Editor: Stuart C. Mangel

Copyright ( 2017 Enrico Sangiovanni et al. This is an open access article distributed under the Creative Commons Attribution License, which permits unrestricted use, distribution, and reproduction in any medium, provided the original work is properly cited.

\begin{abstract}
The involvement of brain-derived neurotrophic factor (BDNF) in different central nervous system (CNS) diseases suggests that this neurotrophin may represent an interesting and reliable therapeutic target. Accordingly, the search for new compounds, also from natural sources, able to modulate BDNF has been increasingly explored. The present review considers the literature on the effects of botanicals on BDNF. Botanicals considered were Bacopa monnieri (L.) Pennell, Coffea arabica L., Crocus sativus L., Eleutherococcus senticosus Maxim., Camellia sinensis (L.) Kuntze (green tea), Ginkgo biloba L., Hypericum perforatum L., Olea europaea L. (olive oil), Panax ginseng C.A. Meyer, Rhodiola rosea L., Salvia miltiorrhiza Bunge, Vitis vinifera L., Withania somnifera (L.) Dunal, and Perilla frutescens (L.) Britton. The effect of the active principles responsible for the efficacy of the extracts is reviewed and discussed as well. The high number of articles published (more than one hundred manuscripts for 14 botanicals) supports the growing interest in the use of natural products as BDNF modulators. The studies reported strengthen the hypothesis that botanicals may be considered useful modulators of BDNF in CNS diseases, without high side effects. Further clinical studies are mandatory to confirm botanicals as preventive agents or as useful adjuvant to the pharmacological treatment.
\end{abstract}

\section{Introduction}

One of the most complete forms of plasticity was described by Donald Hebb in 1949 who proposed an explanation for the adaptation of neurons during cognition and memory; this theory was later summarized by the famous sentence "neurons that fire together, wire together" [1]. Briefly, neuronal plasticity describes the versatility of neuronal connectivity and circuitry to which the nervous system responds and adapts to changing conditions of the body and the environment.

Among the genes involved in the modulation of neuronal activity, neurotrophic factors (NTFs), in particular the neurotrophin family of signaling proteins, play an important role in brain development $[2,3]$ and in adulthood modulating axonal and dendritic growth and remodeling, membrane receptor trafficking, neurotransmitter release, and synapse formation and function [4].

Brain-derived neurotrophic factor (BDNF) as well as nerve growth factor (NGF) is the most studied and bestcharacterized neurotrophins of the central nervous system (CNS), where they are involved in the development and maintenance of physiological brain functions. The features of the BDNF system have been extensively reviewed elsewhere $[5,6]$. Briefly, in rodents, the BDNF gene consists of nine $5^{\prime}$ untranslated exons, each linked to individual promoter regions, and a $3^{\prime}$ coding exon (IX), which codes for the BDNF preprotein amino acid sequence [7]. Similarly, the human $B d n f$ gene is also transcribed through multiple $5^{\prime}$ exons spliced to a single coding exon [8]. The neurotrophin transcription is finely regulated by several intracellular signaling pathways and by different transcription factors [8-11].

Moreover, BDNF function is also highly dependent on translation and posttranslational changes. Indeed, BDNF is initially synthesized as a precursor form (proBDNF, $32 \mathrm{kDa}$ ) that can be cleaved into the mature neurotrophin (mBDNF, $14 \mathrm{kDa}$ ) or transported to the plasma membrane and released in an unprocessed manner. Upon release, the two forms of BDNF protein, as all the neurotrophins, bind with different receptors with multiple and opposite biological functions. The proBDNF binds with high-affinity $\mathrm{p} 75^{\mathrm{NTR}}$ leading to apoptosis, neurite retraction, and synaptic weakening and facilitating long-term depression, whereas mBDNF binds 
with TrkB receptors promoting cell survival, neurite extension, synaptic strengthening, and long-term potentiation (LTP) $[4,12,13]$.

Alterations of NTF expression, including BDNF, are involved in the development of a variety of CNS diseases, including neurodegenerative disorders (Alzheimer's disease, Parkinson's disease, Huntington's disease, and amyotrophic lateral sclerosis) as well as psychiatric disorders (depression and schizophrenia) [14-16]. NTFs may be considered therapeutic targets, but their use has been limited so far by several, still unresolved, methodological problems aimed to guarantee their safety and efficacy $[14,15]$. In particular, results from clinical studies using BDNF as a therapeutic agent have not been encouraging, possibly due to a failure of attaining relevant concentration of the trophic molecule at receptors. The two main problems seem to be related to the inability to deliver BDNF across the blood-brain barrier (BBB) and to the poor bioavailability of BDNF owing to its physiochemical properties [17].

For this reason, alternative options may be devoted to increase the endogenous content of BDNF. Accordingly, several drugs increase, indirectly, BDNF levels; however, considering the high number of nonresponder patients and the presence of serious side effects, the search for new strategies able to interfere with the mechanisms underlying CNS diseases would greatly benefit a high number of subjects. Botanicals are widely consumed all over the world as different types of products, including herbal medicinal products, plant food supplements, and functional foods. Nowadays, they are commonly used for promoting health and treating or preventing a variety of diseases even if, in most cases, clear evidence about their clinical efficacy is lacking. Emerging research provides substantial evidence to classify botanicals as modulators of markers, which are significantly altered during CNS dysfunction.

Some natural products are classified as antidepressants or anxiolytics according to the legislation of the countries in which they are sold $[18,19]$. The ability of a variety of botanicals to positively modulate mood disorders and cognitive impairment resides on understanding that most of them are efficiently absorbed in humans. Recently, biologically active metabolites of botanicals able to interact with multiple targets associated with the promotion of resilience against mood disorders and cognitive impairment in response to stress have been discovered. Interventions with botanicals may benefit anxiety disorders by different mechanisms which include effects on the GABA system either via inducing ion channel transmission or through alteration of membrane structures [20]. A consistent number of botanicals, including Ginkgo biloba L., clinically improve cognitive impairment by ameliorating microvascular function in the brain whereas Bacopa monnieri (L.) Pennell has provided indications as a memory enhancer and protective agent in epilepsy [21].

The aim of the present review is to summarize the relevant literature concerning the role of botanicals as modulators of BDNF (Figure 1). Electronic literature searches were conducted in December 2016 taking into consideration also Epub articles and using Web of Science and PubMed databases. Search limit was the English language whereas no limit was applied for the year of publication. Research articles were searched for title and abstract using the following search terms: Latin name or common name or vernacular name of the plant matched with BDNF. Studies in the literature were found for the following botanicals: Bacopa monnieri (L.) Pennell, Coffea arabica L., Crocus sativus L., Eleutherococcus senticosus Maxim., Camellia sinensis (L.) Kuntze (green tea), Ginkgo biloba L., Hypericum perforatum L., Olea europaea L. (olive oil), Panax ginseng C.A. Meyer, Rhodiola rosea L., Salvia miltiorrhiza Bunge, Vitis vinifera L., Withania somnifera (L.) Dunal, and Perilla frutescens (L.) Britton.

This review emphasizes the part of the plant used, standardization of the active principles, and the protocol to manage studies in addition to the description of the behavioral test employed (Table 1). The effect of the pure compounds occurring in some plant able to modulate BDNF, such as salidroside, caffeine, epigallocatechin-3-O-gallate, and ginsenosides Rg1 and Rb1, will be reviewed as well whereas the effect of the pure compounds curcumin and resveratrol, which have been extensively studied as effective modulators of BDNF, will not be considered in the present review. In addition to the effect of the selected botanicals and/or their active compounds, papers describing biological effects of their association will be also considered.

\section{Bacopa monnieri (L.) Pennell}

Bacopa monnieri (L.) Pennell is a member of Scrophulariaceae traditionally used in Ayurvedic medicine for epilepsy and asthma. The best-characterized compounds occurring in the whole plant are dammarane-type triterpenoid saponins known as bacosides (mostly bacoside A), which are considered the main responsible for the biological activity [22].

2.1. In Vitro Studies. Two studies investigated the protective effect of Bacopa monnieri extract (BME) in vitro. In PC12 cells, pretreatment with a hydroalcoholic extract completely prevented the reduction of BDNF mRNA levels associated with cellular damage induced by scopolamine [23] or sodium nitroprusside [24].

2.2. In Vivo Studies. The effect of Bacopa monnieri was investigated, at preclinical levels, in eight studies using different animal models.

The unpredictable chronic mild stress (CMS), a wellestablished animal model of depression, was used to assess the ability of a compound to exert an antidepressant-like effect. Administration of BME by gavage ( 80 or $120 \mathrm{mg} / \mathrm{kg}$ ) prevented the behavioral deficits and the reduction of $3^{\prime}$ UTR-long BDNF gene expression [25], as well as of the protein levels of the mature form in the hippocampus and frontal cortex of chronically stressed rats [26]. Similar effects were observed after treatment with the tricyclic antidepressant drug imipramine [25-27].

The cognition-enhancing properties of Bacopa monnieri were investigated in the scopolamine rodent model of "cholinergic amnesia" and in the olfactory bulbectomy (OBX), a model of cognitive and emotional dysfunction typical of neurodegenerative pathologies such as Alzheimer's disease [28]. 


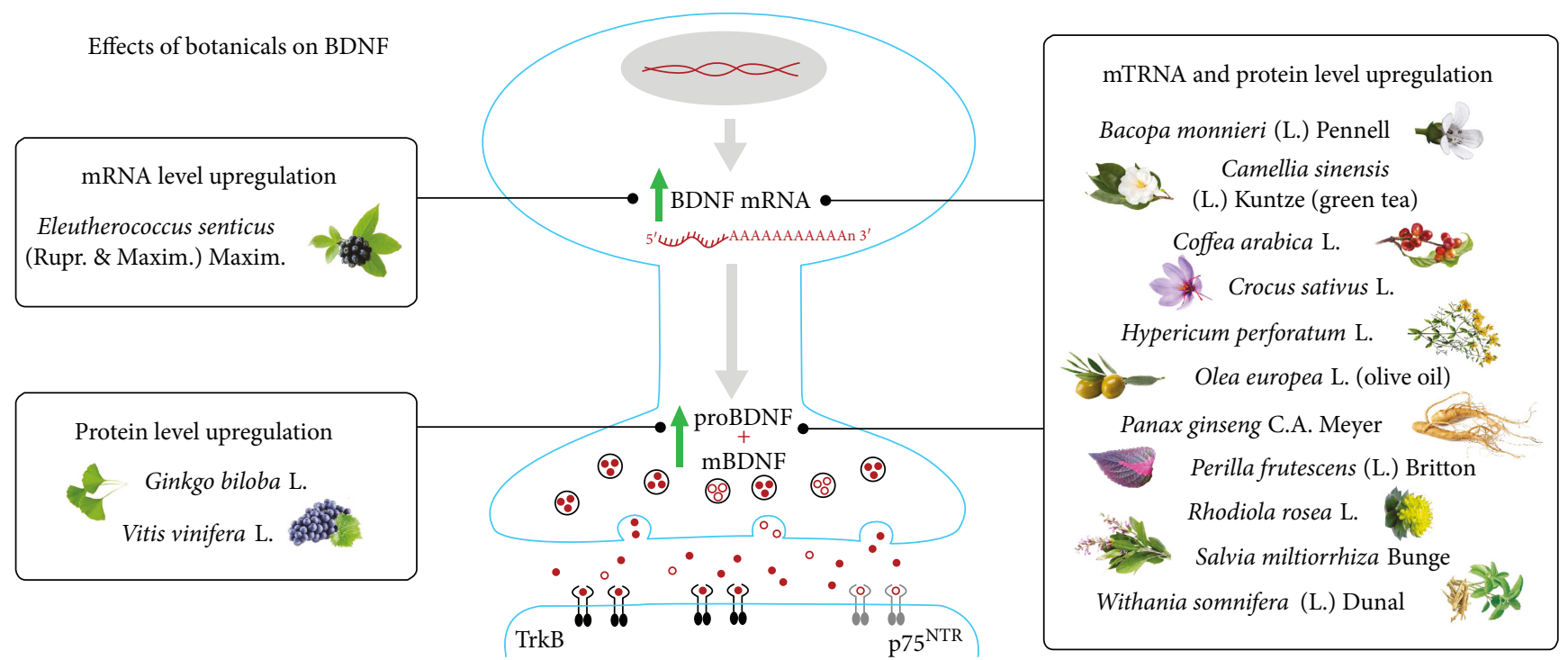

FIGURE 1: Effects of botanicals on BDNF mRNA and protein levels. The figure shows botanicals acting at transcriptional and translational levels.

Interestingly, chronic treatment (62 days) with an alcoholic BME $(50 \mathrm{mg} / \mathrm{kg}$ in the drinking water) ameliorated the memory disturbance and completely normalized the reduction of hippocampal BDNF mRNA levels due to the OBX [29].

Moreover, 1 week of oral (os) treatment with the hydroalcoholic BME $(10,20$, and $40 \mathrm{mg} / \mathrm{kg})$ dose-dependently prevented the memory deficits induced by scopolamine and normalized the reduction of BDNF mRNA levels in the rat hippocampus [30]. A similar effect was found in young mice at postnatal day (PND) 30 [31] treated with CDRI-08 (BME standardized in bacoside A) (3 mg/kg, i.p., 7 days) before and after scopolamine injection. Both the protocols attenuated the decrease in proBDNF protein levels in the mouse cerebrum, caused by scopolamine administration. Furthermore, CDRI-08 per se induced an increase in BDNF gene and protein expression [31].

In a recent study, administration of CDRI- $08(80 \mathrm{mg} / \mathrm{kg}$, i.p., 2 weeks) significantly increased the mRNA and the protein levels of proBDNF in the hippocampus of young rats (PND 32). Interestingly, this effect paralleled the upregulation of the unmethylated $\mathrm{CpG}$ islands 1 and improved the object recognition memory [32]. Using the same regime of treatment, CDRI-08 facilitated memory acquisition in the fear-conditioning paradigm and increased the expression of BDNF exon IV transcript in the hippocampus of PND 30 rats [33].

On this basis, even if clinical studies are needed, preclinical results indicate that Bacopa monnieri extract administration modulates a BDNF effect that may underline its ability as an antidepressant and procognitive agent.

\section{Coffea arabica $\mathbf{L}$.}

The coffee plant, a woody perennial tree growing at higher altitudes, belongs to the family of Rubiaceae. Although beans are particularly rich in caffeine, other constituents are present in a considerable amount, including tocopherols and caffeic acid derivatives, such as chlorogenic acid.

In the literature are present studies reporting the effect of caffeine on BDNF, whereas the effect of a Coffea arabica extract from fruits was investigated only in one clinical study.

3.1. In Vitro Studies. Three studies investigated the in vitro effect of caffeine on BDNF. In particular, caffeine upregulated the BDNF protein levels in mouse hippocampal slices (100 $\mu \mathrm{M}$ for 5 minutes) [34], increased the BDNF release in hippocampal neurons [35], and efficiently stimulated the $\mathrm{BDNF}$ isoform I and IV expression in the presence of $\mathrm{KCl}$ $(10 \mathrm{mM})$ in cortical neurons [36].

3.2. In Vivo Studies. 15 studies investigated the effect of caffeine on BDNF in vivo. Treatment of zebrafish embryos with caffeine $(100 \mu \mathrm{M})$ increased the BDNF mRNA levels specifically after 48 and 72 hours postfertilization [37].

Caffeine administration in naïve rats, during adulthood, counteracted the negative effect exerted by its intake in early life by increasing the protein levels of mBDNF [38]. Differently, administration of caffeine ( $1.0 \mathrm{~g} / \mathrm{L}$ in drinking water) two weeks before mating, during pregnancy, and up to embryonic days 18-20 (E18 or E20) caused a decrease in BDNF protein levels in the whole cortex until E18, while an increase was found at E20 [39].

Caffeine intake during adolescence (from PND 28 to PND 53) by drinking water decreased both proBDNF and $\mathrm{mBDNF}$ in the hippocampus at $1.0 \mathrm{mg} / \mathrm{mL}$, while an increase was found in the cerebral cortex at 0.3 and $1.0 \mathrm{mg} / \mathrm{mL}$ [40]. Interestingly, caffeine at 0.1 or $0.3 \mathrm{mg} / \mathrm{mL}$ improved recognition memory while the highest dose impaired the nonassociative memory [40].

During adulthood to old age, 30 consecutive days of free access to drinking water containing $1 \mathrm{mg} / \mathrm{mL}$ of caffeine solution reduced age-related memory impairment and increased proBDNF in the hippocampus of young adult ( 3 months old) 


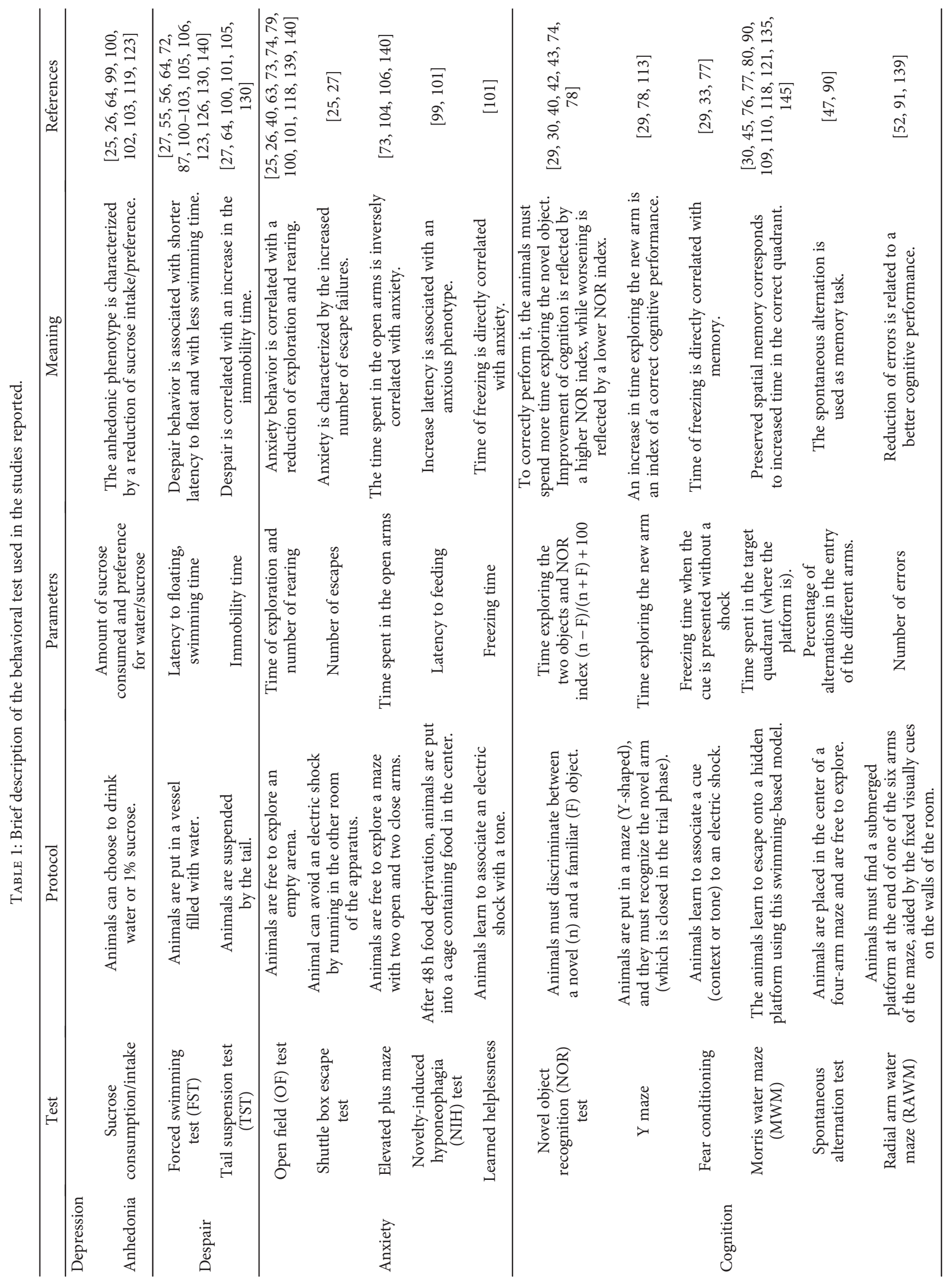


and middle-aged rats (12 months old); the treatment also prevented the age-related increase in the mature form in older rats [41].

Accordingly, prolonged treatment (12 months) with caffeine solution $(1 \mathrm{mg} / \mathrm{mL}$ in drinking water) in 6 -monthold mice counteracted the increase in mBDNF in the hippocampus of aged animals and prevented the age-associated memory decline [42]. Moreover, 4 consecutive days of caffeine treatment $(10 \mathrm{mg} / \mathrm{kg}$, i.p.) increased the protein levels of $\mathrm{mBDNF}$ in the same brain region and improved the performance in the object recognition task in adult mice [43].

In the hippocampus of a mouse model of Alzheimer's disease, induced by $\mathrm{AlCl}_{3}$, cotreatment with caffeine $(1.5 \mathrm{mg} /$ day by gavage) partially prevented the decrease in BDNF gene expression, while the pretreatment completely normalized the impairment [44]. Accordingly, chronic caffeine treatment $(0.75 \mathrm{mg} /$ day or $1.5 \mathrm{mg} /$ day for 8 weeks $)$ dose-dependently increased the mBDNF protein levels in the hippocampus of APP/PS1 (A $\beta$ precursor protein/presenelin-1) double transgenic mice, another model of Alzheimer's disease, and reversed the memory impairment observed in the Morris water maze (MWM) test [45].

Chronic caffeine treatment $(0.33 \mathrm{mg} / \mathrm{L}$ in drinking water $)$ during 4 weeks of psychological stress (intruder model) restored the reduced BDNF protein levels found in the stressed group [46]. The i.p. injection of caffeine once a week was enough to normalize the deficit of BDNF protein levels induced by a high-fat diet. At behavioral level, caffeine fully prevented the diet-induced impairment and restored the spatial memory observed in control animals. Neither diet nor caffeine treatment affected motor activity [47].

Since sleep is a critical factor in memory consolidation and neural plasticity [48], the effect of the chronic caffeine treatment on sleep loss was investigated. Oral administration of caffeine $(60 \mathrm{mg} / \mathrm{kg})$ or the psychostimulant modafinil $(100 \mathrm{mg} / \mathrm{kg})$, at the onset of the light phase during 48 hours of sleep deprivation (SD), restored the normal levels of cell proliferation improving BDNF expression in the dentate gyrus [49]. Accordingly, 4 weeks of caffeine treatment in drinking water $(0.3 \mathrm{~g} / \mathrm{L})$ prevented the SD-induced decrease in neurotrophin levels in the dentate gyrus and in the cornu ammonis-1 (CA1) of the hippocampus [50, 51] and alleviated the impairment in the spatial long-term memory observed in sleep-deprived rats, also through the modulation of $\mathrm{BDNF}$ protein levels [52].

In summary, caffeine affects BDNF protein levels with a specific temporal and dose profile in normal animals. While administration during adulthood or old age increased BDNF, caffeine intake at high doses in early life downregulated the neurotrophin concentration.

Moreover, even if few studies investigated the efficacy of caffeine in animal models of pathology, they provide promising results.

At behavioral levels, caffeine was evaluated as a cognitive enhancer with positive effects.

3.3. Clinical Studies. The clinical study by Reyes-Izquierdo et al. [53] investigated the effect of three different coffee fruit extracts (100 mg dose per os) on BDNF plasma levels in healthy subjects. Coffee fruit concentrate powder (WCFC) ( $0.7 \%$ caffeine) but neither green coffee caffeine (N677) (72.8\% caffeine) nor green coffee bean extract (N625) (2\% caffeine) increased the level of BDNF in blood suggesting that the effect of WFCF might be related to the amount of procyanidins rather than to caffeine [53].

\section{Crocus sativus L.}

Crocus sativus L. belongs to the Iridaceae family; stigmas are commonly known as saffron and are widely cultivated in Iran and used in modern and traditional medicines. The color of saffron is mostly due to the carotenoid named crocin, which is considered among the active principles mostly responsible for neuroprotective activity [54].

4.1. In Vivo Studies. Two in vivo studies investigated the effect of Crocus sativus on BDNF expression. Crocin administration $(12.5 \mathrm{mg} / \mathrm{kg}$, i.p.) for 21 days to naïve male Wistar rats exerted an antidepressant effect and significantly increased the transcription levels of BDNF in the hippocampus [55]. Similarly, chronic treatment with C. sativus aqueous extract $(40,80$, or $160 \mathrm{mg} / \mathrm{kg} / \mathrm{day}$, i.p.), enhanced the gene and protein levels of BDNF in the rat hippocampus. Moreover, at 40 and $160 \mathrm{mg} / \mathrm{kg} / \mathrm{day}$, an antidepressant activity was also observed. Similar results were obtained following imipramine injection $(10 \mathrm{mg} / \mathrm{kg})[56]$.

\section{Eleutherococcus senticosus (Rupr. \& Maxim.) Maxim.}

Eleutherococcus senticosus Maxim. or Acanthopanax senticosus Harms, also called "Siberian ginseng," is a small shrub from the Araliaceae family. Eleutherococcus consists of the whole or cut dried roots of the plant containing lignans, phenylpropanoids, and dicaffeoylquinic acids [57].

5.1. In Vitro Studies. One paper investigated in vitro the effect of Eleutherococcus senticosus on BDNF. A commercial dry aqueous extract of Acanthopanax senticosus stem bark (ASE) normalized the reduction of BDNF mRNA levels produced by the administration of corticosterone $(200 \mu \mathrm{M})$ for $24 \mathrm{~h}$ in PC12 cells. Different concentrations of ASE $(100,200$, and $400 \mu \mathrm{g} / \mathrm{mL})$ significantly increased the mRNA expression of the neurotrophin in a concentrationdependent fashion [58].

Unfortunately, no in vivo or clinical studies are reported in the literature on the modulation of BDNF by E. senticosus, and no clear-cut conclusions can be drawn.

\section{Ginkgo biloba L.}

Ginkgo biloba is an ancient Chinese tree belonging to the family of Ginkgoaceae, cultivated for its health-promoting properties. Although both leaves and seeds are currently used as herbal medicine in China, in many countries, leaves are considered the unique source of active principles and dried green leaves are used for supplying pharmaceutical formulations or extracts as ingredients of food supplements. Ginkgo 
biloba and its constituents were evaluated on BDNF in three in vitro, eight in vivo, and one clinical studies.

6.1. In Vitro Studies. Ginkgo biloba leaf extract (EGb761, $100 \mu \mathrm{g} / \mathrm{mL}$ ) restored the levels of BDNF protein (both pro and mature form) in cells stimulated with appropriate medium able to induce amyloid $\beta$-peptide $\mathrm{A} \beta$ expression.

Administration of individual EGb761 constituents, namely, ginkgolides A (GA), B (GB), C (GC), and J (GJ) and $10 \mu \mathrm{g} /$ $\mathrm{mL}$ bilobalide, increased the levels of BDNF by following a similar pattern [59].

Accordingly, flavonol-enriched extract containing quercetin, kaempferol, and isorhamnetin $(50 \mu \mathrm{g} / \mathrm{mL})$ significantly restored BDNF protein expression in double transgenic APP/ PS1 primary neurons [60].

Moreover, $100 \mu \mathrm{g} / \mathrm{mL}$ of YY162, a patented formula consisting of terpenoid-strengthened Ginkgo biloba and ginsenoside $\mathrm{Rg} 3$, prevented the reduction of BDNF protein levels induced by $48 \mathrm{~h}$ of Aroclor 1254 in SH-SY5Y neuroblastoma cell line [61].

6.2. In Vivo Studies. Ginkgo flavonols ( $50 \mathrm{mg} / \mathrm{kg}$, per os, daily for 4 months) significantly normalized the deficit of BDNF protein levels in the hippocampus of transgenic APP/PS1 mice and improved spatial learning similar to the administration of the antidepressant SSRI (serotonin selective reuptake inhibitor) fluoxetine $(10 \mathrm{mg} / \mathrm{kg})$, while exerting an antidepressant effect on wild-type animals [60].

YY162 (200 mg/kg, per os, from PND 21 to PND 35) significantly attenuated the reduction of BDNF protein in the prefrontal cortex and ameliorated the ADHD- (attention deficit hyperactivity disorder-) like behavioral phenotype induced by Aroclor 1254 [61].

Intravenous (i.v.) injections of EGb761 (45 mg/kg), just before ischemia-reperfusion, induced a significant increase in BDNF positive neurons in the hippocampus with respect to the control group; the treatment significantly reduced the behavior grade measured by a postural reflex test at $24 \mathrm{~h}$ after reperfusion. The effect exerted by EGb761 was comparable to that exerted by the antihypertensive nimodipine $(2 \mathrm{mg} / \mathrm{kg})[62]$.

Chronic treatment with EGb761 (100 mg/kg/day via oral gavage for 30 days) increased the BDNF levels in plasma of both young and aged (18 months) rats, but the effect was not statistically significant; on the opposite, in the aged female group, treatment significantly increased the number of platform crossings in the aged female group in the open field test (OFT) [63].

Pretreatment with EGb761 (100 or $150 \mathrm{mg} / \mathrm{kg} /$ day, per os for 10 days) significantly inhibited the reduction of hippocampal BDNF protein due to LPS (lipopolysaccharide) injections (0.83 mg/kg, i.p.) and showed an antidepressant effect [64]. Furthermore, EGb761 treatment $(50 \mathrm{mg} / \mathrm{kg} / \mathrm{day}$, by oral gavage for 5 weeks) normalized the reduction of BDNF protein levels induced by the first-generation antipsychotic haloperidol injection ( $2 \mathrm{mg} / \mathrm{kg} /$ day, i.p., 5 weeks) in the prefrontal cortex, striatum, substantia nigra, and globus pallidus and reduced the vacuous chewing movement scores over the withdrawal period [65]. Finally, 28 days of treatment with
EGb761 $(40 \mathrm{mg} / \mathrm{kg})$ increased the expression of BDNF and explored the behavior in stressed rats. The effect was comparable to that of the SNRI (serotonin noradrenaline reuptake inhibitor) antidepressant venlafaxine (15 mg/kg) [66]. Administration of bilobalide ( $10 \mathrm{mg} / \mathrm{kg}$, i.p.) for 10 days enhanced the hippocampal protein levels in normal mice more efficiently than that of fluoxetine $(10 \mathrm{mg} / \mathrm{kg})$ [67].

Taken together, these preclinical results suggest that Ginkgo biloba L. administration may be efficacious in restoring BDNF in pathologies characterized by neurotrophin deficits. The main problem is that studies take into consideration different animal models mimicking different kinds of diseases, from Alzheimer's disease to stroke, thus making further results mandatory to confirm the supposed effect on BDNF.

6.3. Clinical Studies. In the unique clinical study, one hundred fifty-seven patients affected by tardive dyskinesia (TD) associated with long-term neuroleptic treatment were randomized to either EGb761 $80 \mathrm{mg}$ three times a day or placebo treatment. EGb761 significantly increased the BDNF protein plasma levels compared with placebo at week 12 in TD patients [68].

\section{Green Tea (Camellia sinensis (L.) Kuntze)}

Tea obtained from the dried leaves of Camellia sinensis (L.) Kuntze (Theaceae) is one of the most widely consumed beverages in the world. Green tea (GT) contains many bioactive compounds including amino acids (i.e., L-theanine), flavonoids (i.e., catechins), and their derivatives, which may constitute up to $30 \%$ of the dried weight [69].

7.1. In Vitro Studies. The potential neuroprotective effect of some constituents of green tea leaves, including catechins, was investigated in two in vitro studies.

L-Theanine pretreatment $(500 \mu \mathrm{M})$ exerted a protective effect by significantly attenuating the downregulation of BDNF protein due to the treatment with two diseaserelated neurotoxicants (rotenone and dieldrin) in the human cell line SH-SY5Y [70].

Moreover, pretreatment with GT catechins, such as epicatechin (EC) and (+)-catechin, prevented the reduction of $\mathrm{mBDNF}$ and the increase in the precursor form induced by the toxic HIV (human immunodeficiency virus) protein Tat [71].

7.2. In Vivo Studies. 10 papers investigated the effects of GT on BDNF. Chronic administration of L-theanine at different doses $(0.2,0.4$, and $10 \mathrm{mg} / \mathrm{kg}$, i.p.) exerted an antidepressant activity and upregulated the protein levels of BDNF in the hippocampus, but not in the cortex of adult mice [72]. Moreover, daily consumption of the flavonol (-)-EC (4 mg/day in water for 14 weeks, ad libitum) in adult mice led to an anxiolytic-like effect and increased the pro and mBDNF levels in the hippocampus, while no effect was found in the cortex [73].

The effect of theanine administration during development was evaluated on rat pups receiving $0.3 \%$ theanine (through lactation before weaning and then directly by 
drinking water) showing increased exploratory activity and enhanced object recognition memory and levels of mBDNF protein in the hippocampus [74].

Assuncao et al. demonstrated that the decrease in BDNF protein levels in the rat hippocampus, associated with aging, was prevented by drinking GT-infused drink as the only drink available from 12 to 19 months of age [75]. Similarly, catechins $(0.05 \%$ and $0.1 \%)$ mixed with drinking water for 6 months improved age-related spatial learning and memory decline of 14-month-old female mice and upregulated the hippocampal mature form of BDNF to levels comparable to those observed in young animals [76].

On the contrary, the addition of epigallocatechin-3-Ogallate (EGCG) $(182 \mathrm{mg} / \mathrm{kg} /$ day $)$ and $\beta$-alanine $(417 \mathrm{mg} / \mathrm{kg} /$ day) to the diet for 4 months did not improve memory and did not alter the mRNA expression of BDNF in the hippocampus of 19-month-old male mice [77].

The GT effect has been studied in different animal models of learning impairments. Administration $(1 \mathrm{~g}$ in $100 \mathrm{~mL}$ water for $5 \mathrm{~min}$ at $100^{\circ} \mathrm{C}$, corresponding to $0.6-$ $1 \mathrm{mg}$ EGCG per day), from gestation to adulthood, corrected the lower BDNF mRNA levels in the hippocampus of mice overexpressing DYRK1A (dual-specificity tyrosine phosphorylation-regulated kinase 1A) but did not affect the performance in memory tasks [78].

In senescence-accelerated mice-prone 8 (SAMP8), a model characterized by the early onset of learning and memory deficits along with overproduction of soluble amyloid peptide in the brain, the chronic treatment with green tea catechins (GTC) $(0.05 \%$ and $0.1 \%$ in drinking water for 6 months) restored the reduction of mBDNF levels in the hippocampus and prevented the learning impairment of SAMP8 mice [79]. Finally, 4 months of EC administration $(50 \mathrm{mg} / \mathrm{kg}$ daily in drinking water) normalized the low levels of BDNF protein in the hippocampus of 8-month-old APP/PS1 mice, without affecting escape latency in MWM [80].

Teasaponin $(10 \mathrm{mg} / \mathrm{kg}$, i.p. for 21 days $)$ rescued the upregulation of BDNF induced by the adipocyte-secreted hormone leptin in the prefrontal cortex of high-fat diet-fed mice. In addition, teasaponin $(20$ or $40 \mu \mathrm{M})$ reversed the effect of palmitic acid on the alteration induced by leptin in cultured cortical neurons [81].

To summarize, these studies provide robust evidence regarding the role of green tea as a modulator of BDNF and in improving cognitive performance at preclinical levels.

\section{Hypericum perforatum $\mathrm{L}$.}

Hypericum perforatum L. (HYP), known as St John's wort, is a plant belonging to the family of Hypericaceae. Flowering aerial parts are used in many countries for their antidepressant activity, mostly ascribed to the active principles hyperforin, hypericin, and pseudohypericin $[18,57]$.

8.1. In Vivo Studies. The antidepressant activity of Hypericum perforatum was investigated at preclinical level in two in vivo studies using the CMS animal model. The chronic treatment with hydroalcoholic extract of HYP $(350 \mathrm{mg} / \mathrm{kg}$ per os, 21 days) normalized the reduction of mRNA expression of
BDNF found in the hippocampus of stressed mice [82]. On the contrary, Butterweck et al. showed that the chronic administration of HYP methanolic extract $(500 \mathrm{mg} / \mathrm{kg}$, per os) did not prevent the stress-induced decrease in BDNF mRNA levels in the rat hippocampus, produced by the immobilization stress protocol ( $2 \mathrm{~h}$ once a day for 7 days) [83]. The different outcomes between these two preclinical studies could be due to the type of stressors or the protocol of treatment used.

8.2. Clinical Studies. In one large cohort of subjects, chronic HYP treatment restored the normal protein concentration of BDNF in the serum of depressed patients. This normalization was limited to HYP and serotonin reuptake inhibitors, whereas other classes of antidepressants, including the tricyclics and the noradrenergic and specific serotoninergic antidepressant, were ineffective. The limitation of this study is that the dose of the different drugs used is not clearly indicated [84].

\section{Olive Oil (Olea europaea L.)}

Olive oil is the main source of fat in the Mediterranean-style diet. Health benefit of olive oil consumption has been in part ascribed to minor phenol components (i.e., oleuropein, ligstroside aglycones, and hydroxytyrosol (HT)) whose composition varies qualitatively and quantitatively depending on the stage of fruit ripeness or the region of cultivation $[85,86]$.

9.1. In Vivo Studies. Five animal studies were performed to test the effect of olive oil components on BDNF. The administration of a mixture of olive oil polyphenols extracted from the olive residues (pomace) $(10 \mathrm{mg} / \mathrm{kg}$, i.p., 10 days) significantly increased the BDNF protein levels in the hippocampus and in the olfactory lobes, while decreasing the neurotrophin in the frontal cortex [87]. Moreover, this regime of treatment did not affect pain sensitivity in the hot-plate test or stress response in the FST in naïve animals [87].

Differently, if the blend of polyphenols was extracted from olive leaves $(20 \mathrm{mg} / \mathrm{kg}$, i.p. for 15 days), BDNF protein levels were downregulated in the hippocampus and striatum and upregulated in the olfactory lobes. Polyphenol administration significantly increased the concentration of BDNF protein in the mouse serum [88]. Interestingly, a diet enriched in olive oil components during prenatal life until weaning induced, at adulthood, an upregulation of the mRNA levels of the total BDNF and of the isoforms IV and VI in the prefrontal cortex but not in the hippocampus [89].

Before mating, the treatment with HT (10 or $50 \mathrm{mg} / \mathrm{kg} /$ day by gavage for 2 weeks), one of the most bioactive phenolic compound in olive oil, prevented the significant decrease in proBDNF and mBDNF due to prenatal stress exposure in male offspring and improved cognitive functions [90].

In Alzheimer's disease mouse model, HT chronic treatment $(10 \mathrm{mg} /$ day by gavage for 14 days) attenuated the spatio-cognitive deficits and normalized the hippocampal BDNF mRNA levels [91].

9.2. Clinical Studies. The effect of olive oil was investigated in two clinical studies. Taking Mediterranean diet supplemented 
with olive oil for 3 years did not alter the plasma BDNF protein levels in normal subjects [92]. Moreover, the administration of a blend of olive polyphenols (a tablet containing a total of $50 \mathrm{mg} /$ day) extracted from the olive pomace and containing mostly HT and oleuropein for 15 consecutive days in alcoholic patients undergoing withdrawal induced a transient decrease in $\mathrm{mBDNF}$ protein levels in the serum after 3 days of treatment [93].

Even if not so many, in vivo studies provide positive results, while the effect in clinical studies (only 2) appears inconsistent or negligible.

\section{Panax ginseng C.A. Meyer}

Ginseng radix consists of the whole or cut dried root of Panax ginseng C.A. Meyer and contains not less than $0.4 \%$ of the sum of ginsenosides Rg1 (Rg1) and Rb1 (Rb1). Ginsenosides are triterpenoid saponins which are the main responsible for the biological activities of ginseng extracts [57].

10.1. In Vitro Studies. Five studies were performed in vitro to test the effect of ginseng or ginsenosides on BDNF. Rg1 treatment upregulated the mRNA expression and protein secretion of BDNF in primary cultured olfactory cells (Rg1, $40 \mu \mathrm{g} / \mathrm{mL}$ for $72 \mathrm{~h}$ ) [94] and in Schwann cells (Rg1, 50 $\mu \mathrm{M}$ for $24 \mathrm{~h}$ ) challenged with $0.2 \% \mathrm{H}_{2} \mathrm{O}_{2}$ for $4 \mathrm{~h}$ [95]. The beneficial effect was also found in different "pathological conditions." Indeed, pretreatment of rat brain slices with $\operatorname{Rg} 1$ at different concentrations $(60,120$, and $240 \mu \mathrm{M}$ for $2 \mathrm{~h}$ ), before okadaic acid administration, increased the BDNF protein expression in a dose-dependent fashion [96].

Red ginseng extract (RGE) $(0.01-1.0 \mathrm{mg} / \mathrm{mL}$ applied for $1 \mathrm{~h})$ dose-dependently increased the BDNF protein expression in primary cultures of rat hippocampal neurons exposed for $48 \mathrm{~h}$ to $100 \mu \mathrm{M}$ kainic acid [97]. BDNF protein levels were significantly increased in PC12 cells subjected to oxygen glucose deprivation/reperfusion (OGD/R) for $4 \mathrm{~h}$ by ginsenoside $\mathrm{Rd}(\mathrm{Rd})$ at 50 and $100 \mu \mathrm{M}$ [98].

10.2. In Vivo Studies. A total number of 25 studies were performed in vivo, mostly on pure ginsenosides.

Deficits induced at protein levels by the exposure to CMS were normalized by concomitant treatment with ginseng standardized in the saponin content (GTS) $(50$ and $100 \mathrm{mg} /$ $\mathrm{kg}$ ) [99] or $\operatorname{Rg} 1(2.5,5,10$, and $20 \mathrm{mg} / \mathrm{kg}$, i.p.) [100] in the hippocampus and with ginsenoside Rb3 (Rb3) (30, 75, and $150 \mathrm{mg} / \mathrm{kg}$, intragastrically) both in the prefrontal cortex and in the hippocampus [101]. At $40 \mathrm{mg} / \mathrm{kg}$ (i.p.), the effect, for Rg1, was also found in the lateral amygdala [102, 103]. Rg1 corrected the alteration found at translational level [100] similar to fluoxetine $(10 \mathrm{mg} / \mathrm{kg})[104,105]$ and imipramine [100]. Moreover, all the compounds reverted the behavioral phenotype associated with this model [99-103].

A comparable effect was found after chronic restraint stress with $\operatorname{Re}(50 \mathrm{mg} / \mathrm{kg})$ and fluoxetine $(10 \mathrm{mg} / \mathrm{kg})$ at transcriptional level in the hippocampus [106], while Rg1 $(10 \mathrm{mg} / \mathrm{kg})$ prevented the reduction of $\mathrm{mBDNF}$ in the prefrontal cortex [107]. Re produced an antidepressant and anxiolytic effect [106], whereas Rg1 improved learning and memory [107].

The decreased expression of BDNF mRNA, found after the single prolonged stress, was significantly restored to normal level by chronic treatment with Rb1 (10 or $30 \mathrm{mg} / \mathrm{kg}$, i.p., 14 days) or fluoxetine $(10 \mathrm{mg} / \mathrm{kg}) . \mathrm{Rb} 1$ at $30 \mathrm{mg} / \mathrm{kg}$ normalized the percentage of time spent in the open arms in the elevated plus maze [104]. Rb1 (10 mg/kg), administered $30 \mathrm{~min}$ before acute immobilization stress, significantly inhibited the stress-mediated decline in BDNF mRNA level [108].

Accordingly, GTS (25 or $50 \mathrm{mg} / \mathrm{kg} /$ day), similar to fluoxetine $(10 \mathrm{mg} / \mathrm{kg})$, significantly upregulated the mRNA and protein levels of BDNF in the hippocampus of corticosterone-treated mice $(20 \mathrm{mg} / \mathrm{kg}$, once a day for 22 days) but not in that of normal animals and produced an antidepressant effect [105].

Panax ginseng extract or pure compounds exerted a positive effect also on the scopolamine animal model. Indeed, wild ginseng (WG) roots $(200 \mathrm{mg} / \mathrm{kg}$, i.p.) normalized the mRNA level of BDNF in the rat hippocampus of the scopolamine-treated group, as well as reducing the escape latency in the MWM test [109]. Accordingly, pretreatment with ginsenosides $\operatorname{Rg} 5$ (Rg5) and Rh3 (Rh3) (5, 10, and $20 \mathrm{mg} / \mathrm{kg}$, per os) inhibited the reduction of $\mathrm{mBDNF}$ protein expression induced by scopolamine injection $(1 \mathrm{mg} / \mathrm{kg}$, i.p.) and reduced the latency time in MWM. The protective effect of Rh3 (5 and $10 \mathrm{mg} / \mathrm{kg}$ ) on memory deficit was more potent than that of Rh5 and comparable with that of the acetyl cholinesterase inhibitor donepezil $(5 \mathrm{mg} / \mathrm{kg})$ used in the treatment of Alzheimer's disease [110].

Oral administration of $\operatorname{Rg} 5(5,10$, and $20 \mathrm{mg} / \mathrm{kg})$ or donepezil $(3 \mathrm{mg} / \mathrm{kg})$ prevented the reduction of $\mathrm{mBDNF}$ induced by streptozotocin (STZ) ( $3 \mathrm{mg} / \mathrm{kg}$ intracerebroventricular administration) and enhanced the memory retention, the mean latency time, and the path length with respect to the STZ group in the MWM test [111].

Rd $(10,20,40$, and $80 \mathrm{mg} / \mathrm{kg} /$ day, i.p.) prevented the reduction of $\mathrm{BDNF}$ expression in both the cerebral cortex and lumbar spinal cord in an animal model of encephalomyelitis [112].

Rg1 (2.5, 5.0, and $10 \mathrm{mg} / \mathrm{kg}$, i.p.) significantly increased, in a dose-dependent manner, the mBDNF protein level in SAMP8 mice and ameliorated the cognitive impairments observed in 9-month-old mice [113].

Similarly, chronic treatment with $\mathrm{Rg} 1$ (1 mg/kg or $10 \mathrm{mg} /$ $\mathrm{kg}$, i.p. for 30 days) significantly enhanced the mBDNF expression in the hippocampal homogenate of middle-aged rats. Also, proBDNF was upregulated, but the effect was significant only for the $10 \mathrm{mg} / \mathrm{kg}$-treated group. Furthermore, Rg1 administration significantly improved the memory in the fear-conditioning task [114].

The protective effect of Rg1 on memory performance and synaptic plasticity was assessed in a transgenic AD model constructed by overexpressing APP and PS1. The injection of $10 \mathrm{mg} / \mathrm{kg}$ Rg1 for 30 days (i.p.) upregulated the BDNF protein levels and ameliorated the memory in mice [115].

Moreover, in adult male rats, Rb1 infusion $(40 \mathrm{mg} / \mathrm{kg}$ ) significantly increased the BDNF protein expression from $3 \mathrm{~h}$ to 10 days after middle cerebral artery reperfusion, with 
a peak at 3 days [116]. On the opposite, treatment with $\mathrm{Rb} 1$ $(7.5 \mathrm{mg} / \mathrm{mL})$ by intragastric administration for three days, three times a day $(12.5 \mathrm{~mL} / \mathrm{kg}$ weight $)$ before transient middle cerebral artery occlusion, did not prevent the increased levels of BDNF due to the damage. Indeed, BDNF protein levels were higher in the $\mathrm{Rb} 1$ group compared to the untreated animals [117].

Five- to 7-week-old male C57BL/6J mice were treated with $\mathrm{Rd}$ ( 10 or $30 \mathrm{mg} / \mathrm{kg}$, i.p. for 21 days) fifteen days after bilateral carotid artery stenosis that induced chronic cerebral hypoperfusion $(\mathrm{CCH})$. The dramatic decrease in BDNF protein and mRNA levels observed in the $\mathrm{CCH}$ model was reversed by $\mathrm{Rd}$ administration that also improved the memory task performance [118].

YY162 significantly reduced the BDNF protein decline in the prefrontal cortex and improved the ADHD behavioral phenotype [61].

Pretreatment for 3 days with $\mathrm{Rg} 1$ (10 or $30 \mathrm{mg} / \mathrm{kg}$, i.p.) or the antibiotic minocycline $(30 \mathrm{mg} / \mathrm{kg}$, i.p.) significantly normalized the BDNF mRNA levels altered by a central injection of LPS ( $5 \mu \mathrm{g}$ in $5 \mu \mathrm{L}$ saline) in the cortex but not in the hippocampus.

Rg1 administration at both low and high doses alleviated the anorexic symptoms and increased the sucrose preference [119].

The effect of ginsenoside administration on naïve animals is conflicting. Indeed, injections of Rb1 $5 \mathrm{mg} / \mathrm{kg} / \mathrm{day}$ in $0.2 \mathrm{cc}$ saline i.p. for 4 days did not modulate the BDNF mRNA levels in the hippocampus [120], while ginsenoside Rh1 (10 mg/kg/day for 3 months) significantly upregulated the BDNF protein levels in the hippocampus with respect to the control group. The Rh1-treated group (5 and $10 \mathrm{mg}$ / $\mathrm{kg}$ ) significantly promoted the spatial learning ability in the MWM test [121]. Finally, administration of gintonin (50 mg/kg per os, 7 days), a mixture of glycolipoproteins from Panax ginseng, significantly increased the BDNF protein levels [122].

Taken together, reviewed studies suggest that pure ginsenosides are effective modulators of neuroplasticity. The main criticism is the heterogeneity of the studies that evaluate the effect of each ginsenoside at a time.

\section{Perilla frutescens (L.) Britton}

Perilla frutescens (L.) Britton, also called $z i$-su in Chinese, is an annual herb belonging to the Lamiaceae family; stems, leaves, and seeds are widely used in traditional Chinese medicine or as food ingredients.

11.1. In Vivo Studies. Five papers investigated the effect of Perilla frutescens on in vivo models. Administration of essential oil from commercial Perilla leaf (EOPL) for 4 weeks, at 3 or $6 \mathrm{mg} / \mathrm{kg}$, normalized the BDNF gene expression, while only the highest dose was effective at protein levels in the hippocampus of chronically stressed mice. Conversely, 3 weeks of EOPL was not enough to correct the molecular deficit observed. Moreover, EOPL produced an antidepressant-like effect in the sucrose preference test after 3 and 4 weeks at both concentrations and in the FST at $6 \mathrm{mg} / \mathrm{kg}$ after 3 -week treatment or at $3 \mathrm{mg} / \mathrm{kg}$ and $6 \mathrm{mg} / \mathrm{kg}$ after 4 -week treatment, while no effect was observed on the locomotor activity. Interestingly, a similar effect was found in administering $20 \mathrm{mg} / \mathrm{kg}$ fluoxetine [123].

Male mice subjected to dietary restriction of $\alpha$-linolenic acid (ALA) were fed with a diet supplemented with Perilla oil (5\%) for 8 weeks. ALA restriction lowered the BDNF levels in the striatum, and Perilla oil significantly increased the BDNF protein levels $[124,125]$.

Six weeks of Perilla seed oil administration at $4 \%(w / w)$ in the diet to naïve Sprague-Dawley rats significantly upregulated the concentration of BDNF in the prefrontal cortex, while the immobility times were significantly shorter in the FST. A similar effect was observed after i.p. injection of imipramine $(30 \mathrm{mg} / \mathrm{kg})$ [126].

In a recent study, chronic treatment with Perilla oil ( $500 \mathrm{mg} / \mathrm{kg} /$ day by gastric gavage) normalized the decrease in BDNF protein levels in an animal model of Alzheimer's disease. The effect paralleled the anxiolytic-like effect and improved the cognitive performance measured in both the novel object recognition test and the MWM test [127].

On these bases, the few studies present in literature are encouraging, but other demonstrations are mandatory to draw clear-cut conclusions.

\section{Rhodiola rosea $\mathrm{L}$.}

Rhodiola rosea L. (Crassulaceae) has a long history of use as a medicinal plant in several traditional medicines. Rhodiola root and rhizome increase the organism's resistance to physical, chemical, and biological stressors; the effect is mostly due to the active principle salidroside (SA, syn. rhodioloside) [128].

12.1. In Vitro Studies. One in vitro study evaluated the effect of SA on BDNF demonstrating that the pure compound induced mesenchymal stem cells to differentiate into dopaminergic neurons. Moreover, SA treatment $(100 \mu \mathrm{g} / \mathrm{mL})$ for 1-6 days significantly increased the BDNF mRNA levels while at 12 days, an opposite effect was found. Differently, the effect on the BDNF protein levels was more long lasting since it was still present after 12 days [129].

12.2. In Vivo Studies. In vivo, the treatment for 5 days (12 and $24 \mathrm{mg} / \mathrm{kg}$, per os) with SA or fluoxetine prevented the development of the depression-like behavior and of the downregulation of BDNF protein levels in the hippocampus induced by a single injection of LPS [130].

\section{Salvia miltiorrhiza Bunge}

Salvia miltiorrhiza Bunge (Lamiaceae), also known as red sage, is a perennial plant; root and rhizome are widely used in China for the treatment of cardiovascular and cerebrovascular diseases [131].

13.1. In Vitro Studies. Two in vitro studies evaluated the effect of salvianolic acid B (SalB). Treatment with SalB $(20 \mu \mathrm{g} / \mathrm{mL}$, for $24 \mathrm{~h}$ ) significantly increased the level of BDNF protein in bone marrow-derived neural stem cells [132]. 
Furthermore, SMND-309 (5, 10, and $20 \mu \mathrm{M}$ for $24 \mathrm{~h})$, the metabolite produced in the brain and heart of rats after SalB oral administration, restored the mBDNF protein expression in the human neuroblastoma cell line SH-SY5Y subjected for $2 \mathrm{~h}$ to $\mathrm{OGD} / \mathrm{R}[133]$.

13.2. In Vivo Studies. Salvia miltiorrhiza extracts and pure compounds were also investigated in five in vivo studies. Hippocampal BDNF immunoreactivity was markedly decreased by the injection of the $\mathrm{A} \beta_{25-35}$ peptide in mice, and subchronic treatment with SalB $(10 \mathrm{mg} / \mathrm{kg}, 7$ days $)$ reversed this reduction [134]. A similar effect was observed after oral treatment for 14 days $(0.81$ and $0.405 \mathrm{~g} / \mathrm{kg})$ with the formulation named Compound Danshen Tablet (CDT) (Salvia miltiorrhiza, Panax notoginseng, and borneol in a ratio $450: 141: 8$ ). Indeed, CDT administered to mice at $0.81 \mathrm{~g} / \mathrm{kg}$ or $0.405 \mathrm{~g} / \mathrm{kg}$ normalized the hippocampal BDNF mRNA levels and improved the cognitive performance, while the lowest dose was effective also at the protein level [135].

Pretreatment with tanshinone I $(10 \mathrm{mg} / \mathrm{kg}$, i.p. for 3 days), a lipophilic diterpenoid occurring in the radix of Salvia miltiorrhiza, administered 5 minutes before ischemiareperfusion by bilateral common carotid artery occlusion, corrected the reduced BDNF immunoreactivity in the CA1 of ischemic Mongolian gerbils [136]. Similarly, salvianolic acid $\mathrm{A}(100 \mu \mathrm{g} / \mathrm{kg})$ administered intravenously $2 \mathrm{~h}$ after middle cerebral artery occlusion/reperfusion significantly reversed the protein levels of $\mathrm{mBDNF}$ in the ipsilateral ischemic brain hemisphere. Furthermore, the treatment significantly improved the reduction in tracking distance induced by stroke injury [137].

Salvianolate lyophilized injection $(10.5,21$, and $42 \mathrm{mg}$ / $\mathrm{kg}$ ) ameliorated the deficits observed in diabetic rats after stroke normalizing the protein level of the mature form of BDNF [138].

\section{Vitis vinifera L. (Red Wine)}

Vitis vinifera L. is a plant belonging to the family of Vitaceae, native to the Mediterranean region and widely used to make wine or juice.

14.1. In Vivo Studies. Two in vivo studies were performed on male rats. Grape powder (including that of fresh red, green, and blue-black California grapes, seeded and seedless varieties) dissolved in tap water $(15 \mathrm{~g} / \mathrm{L})$ for 3 weeks attenuated the reduction of BDNF protein levels induced by the oxidative stress mediator L-buthionine-(S,R)-sulfoximine in the amygdala, hippocampus, and cortex [139] or due to the exposure to a single prolonged stress [140]. Moreover, grape intake exerted an anxiolytic effect and a positive effect in the memory test $[139,140]$. In addition to grape studies, few interesting papers investigated BDNF modulations by red wine or ethanol starting from 60 days before pregnancy up to pup weaning. Adult animals exposed to only ethanol showed disrupted levels of BDNF in several brain areas, including the hippocampus, and altered cognition and emotional behavior. Conversely, mice exposed to red wine had no changes in the behavior but a decrease in hippocampal BDNF [141]. Another study investigated BDNF changes in old male mice following perinatal exposure to ethanol or red wine at the same ethanol concentration. The study demonstrates that ethanol alone is able to increase BDNF levels in limbic areas, whereas, in mice exposed to red wine, BDNF levels were comparable to those of control thus allowing one to hypothesize a protective role of wine polyphenols against the damaging effect of ethanol alone [142].

14.2. Clinical Studies. One clinical study was performed on 25 healthy fasted subjects treated with a single dose of grape seed extract (N31, 72\% polyphenols). The participants were 18-55 years old and had a body mass index between 18.0 and $25.0 \mathrm{~kg} / \mathrm{m}^{2}$. N31 increased the BDNF levels in plasma by $30 \%$ with respect to the baseline, although the effect was not statistically significant [53].

\section{Withania somnifera (L.) Dunal}

Withania somnifera (L.) Dunal, also called Ashwagandha or Indian ginseng (Solanaceae), is a traditional Ayurvedic remedy reputed to be useful as an antistress and memory enhancer [143].

15.1. In Vivo Studies. Two papers investigated the effect of Withania somnifera on in vivo models. Pretreatment with an alcoholic extract of Ashwagandha leaves (100 mg, $200 \mathrm{mg}$, and $300 \mathrm{mg} / \mathrm{kg}$ for 7 days) significantly prevented the effects due to the scopolamine treatment $(3 \mathrm{mg} / \mathrm{kg})$ such as the reduction of the mRNA expression of BDNF transcript variant- 1 and of proBDNF and mBDNF protein expression at all the concentrations tested. On the contrary, posttreatment at $200 \mathrm{mg} / \mathrm{kg}$ was ineffective [144].

Withanolide-enriched extract from the Withania somnifera root (methanol-water 25:75, v/v) was evaluated on induced hypobaric hypoxia in rats. Animals fed before and after hypobaric hypoxia with $200 \mathrm{mg} / \mathrm{kg}$ of the extract showed an increased expression of BDNF and a significant decrease in latency and path length in the MWM test [145].

\section{Conclusions}

In this review, we provide an upgrade of the current literature on the ability of some well-known botanicals to modulate BDNF expression in the brain. Recently, the strategy searching for new compounds, also from natural sources, able to modulate neurotrophin levels, has been increasingly explored. The growing interest in the use of botanicals as modulators of the CNS diseases is proved by the large amount of scientific papers we retrieved and reviewed on this topic (more than one hundred papers for 14 botanicals) (Figure 2). Results critically reviewed and discussed herein emphasize how botanicals modulate BDNF in different pathological conditions affecting the CNS, providing an alternative strategy to the conventional treatment. Indeed, most of the studies demonstrated that treatment with botanicals may prevent and/or normalize 


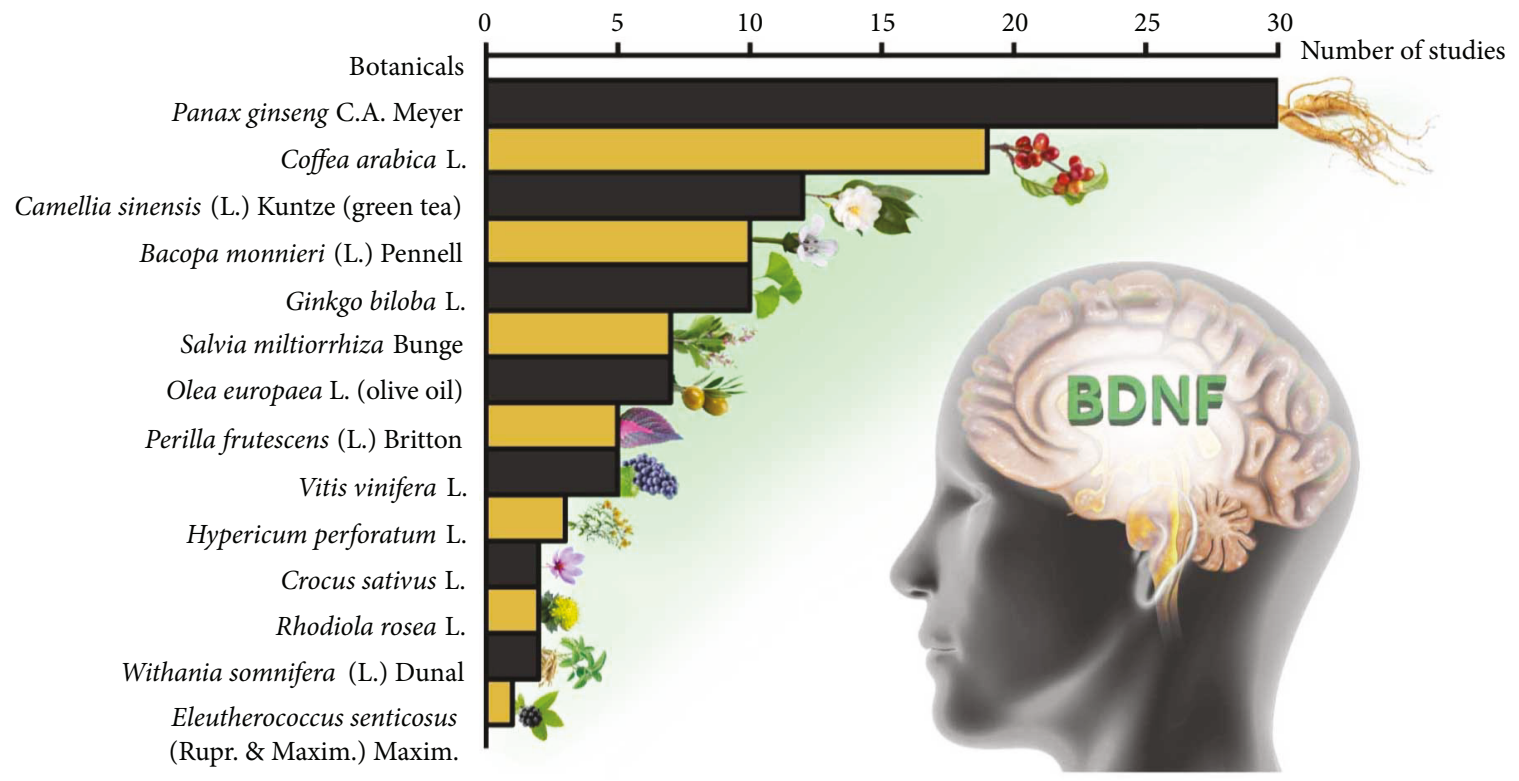

FIGURE 2: Number of studies investigating BDNF in the central nervous system for each botanical or active principle.

the alterations of BDNF caused by experimental handling (Table 2).

An added value of papers dealing with in vivo studies is that molecular analyses parallel the investigation of an animal model's behavior after treatment, thus allowing one to draw clear-cut conclusions on the functional outcome associated with the correction of the molecular deficits.

Indeed, despite a variety of different pathological conditions taken into consideration, from mood disorders to Alzheimer's disease and aging up to cerebral vascular damage, the common point is the impairment of cognition. Accordingly, among the behavioral phenotypes, the performance in learning and memory tasks was deeply explored as a common feature of different diseases occurring in the CNS and many botanicals considered have been demonstrated to have cognitive-enhancing properties such as Bacopa monnieri, Coffea arabica, Ginkgo biloba, green tea, olive oil, Panax ginseng, Perilla frutescens, Salvia miltiorrhiza, Vitis vinifera, and Withania somnifera.

This observation increases the meaning of the results summarized in the present review because the positive effect on a molecular target (BDNF) and on a functional deficit (in cognition) altered in several diseases makes the therapeutic ability of these compounds broad-spectrum.

Another point is that most studies compared the effect of botanicals with the effect obtained from a reference drug, showing similar efficacy. For example, Bacopa monnieri, Crocus sativus, Ginkgo biloba, green tea, Panax ginseng, Perilla frutescens, and Rhodiola rosea exert antidepressantlike effects in different behavioral tests compared to the classical drugs used in therapy. However, most of the clinical studies reported in the present review do not pay attention to the side effects following botanical treatment.

Moreover, even if promising results have been found on Crocus sativus, Eleutherococcus senticosus Maxim., Hypericum perforatum, Rhodiola rosea, Salvia miltiorrhiza Bunge,
Vitis vinifera, and Withania somnifera Dunal and BDNF modulation, the number of studies of these botanicals is too low for drawing conclusive results.

The current revision of the literature suggests that several issues need to be considered to draw consistent conclusions. Firstly, considering the complexity of the BDNF system, as briefly described in the introduction, a more refined analysis of the different elements both at transcription and translational levels is mandatory. Indeed, very few studies report the BDNF isoform or the form measured, and, in some cases, the molecular weight of the band examined does not correspond to either the mature or the precursor form.

Secondly, though not negligible, the number of clinical studies is very limited since few clinical trials have been found in literature. Among them, the first was carried out in schizophrenic patients following treatment with Ginkgo biloba L. extract [68] and the second was performed in depressed patients treated with Hypericum perforatum L. [84], whereas the others were performed in healthy subjects. Although the effect obtained from those studies was relevant, the paucity of clinical trials implies that botanicals discussed in the present review need to be carefully considered for human studies.

Standardization of the extract is an important prerequisite for efficacy of botanicals. Knowledge of the active principles is the first step for an adequate standardization. Results reported in literature show that ginsenosides are mostly responsible for BDNF modulation exerted by Panax ginseng C.A. Meyer whereas rhodioloside appears to be the main active principle occurring in Rhodiola rosea L. However, for other botanicals, the molecules driving the pharmacological effects are not clearly defined (i.e., Vitis vinifera L. or olive oil (Olea europaea L.)) and only speculations can be done at this regard. Thus, it is important to underline that most of the studies reviewed herein used standardized extracts, 
TABLE 2: Summary of the experimental conditions employed to investigate the effect of botanical administration on BDNF expression.

\begin{tabular}{|c|c|c|c|c|c|}
\hline Botanicals & Type of studies & Models & mRNA & Protein & References \\
\hline \multirow{8}{*}{ Bacopa monnieri (L.) } & In vitro & PC12 & $\bullet$ & & {$[23,24]$} \\
\hline & \multirow{7}{*}{ In vivo } & Naïve animals & $\bullet$ & $\bullet$ & {$[32]$} \\
\hline & & Chronic stress & $\bullet$ & - & {$[25,27]$} \\
\hline & & & & $\bullet$ & {$[26]$} \\
\hline & & Fear conditioning & - & & [33] \\
\hline & & Olfactory bulbectomy & $\bullet$ & & [29] \\
\hline & & Scopolamine & $\bullet$ & & {$[30]$} \\
\hline & & & $\bullet$ & $\bullet$ & {$[31]$} \\
\hline \multirow{11}{*}{ Coffea arabica $\mathrm{L}$. } & \multirow{3}{*}{ In vitro } & Hippocampal neurons & & - & {$[34,35]$} \\
\hline & & Cortical neurons & - & & {$[36]$} \\
\hline & & Naïve animals & & - & {$[38-43]$} \\
\hline & \multirow{7}{*}{ In vivo } & & - & & {$[37]$} \\
\hline & & Alzheimer's disease & - & & {$[44]$} \\
\hline & & & & $\bullet$ & {$[45]$} \\
\hline & & Chronic stress & & $\bullet$ & {$[46]$} \\
\hline & & Obesity (high-fat diet) & & $\bullet$ & {$[47]$} \\
\hline & & Sleep deprivation & $\bullet$ & & [49] \\
\hline & & & & $\bullet$ & {$[50-52]$} \\
\hline & Clinical & Healthy subjects & & - & {$[53]$} \\
\hline Crocus sativus $\mathrm{L}$. & In vivo & Naïve animals & $\bullet$ & $\bullet$ & {$[55,56]$} \\
\hline $\begin{array}{l}\text { Eleutherococcus senticosus } \\
\text { (Rupr. \& Maxim.) Maxim. }\end{array}$ & In vitro & PC12 & $\bullet$ & & {$[58]$} \\
\hline \multirow{11}{*}{ Ginkgo biloba L. } & \multirow{3}{*}{ In vitro } & $\mathrm{N} 2 \mathrm{a}$ & & $\bullet$ & [59] \\
\hline & & (APP/PS1) primary neurons & & - & {$[60]$} \\
\hline & & SH-SY5Y & & $\bullet$ & {$[61]$} \\
\hline & \multirow{7}{*}{ In vivo } & Naïve animals & & $\bullet$ & {$[63,67]$} \\
\hline & & Alzheimer's disease & & $\bullet$ & {$[60]$} \\
\hline & & $\mathrm{ADHD}$ & & $\bullet$ & {$[61]$} \\
\hline & & Cerebral ischemia-reperfusion & & $\bullet$ & {$[62]$} \\
\hline & & Chronic stress & & $\bullet$ & {$[66]$} \\
\hline & & Haloperidol & & $\bullet$ & {$[65]$} \\
\hline & & LPS-induced depression & & $\bullet$ & {$[64]$} \\
\hline & Clinical & Tardive dyskinesia patients & & $\bullet$ & {$[68]$} \\
\hline \multirow{7}{*}{$\begin{array}{l}\text { Green tea } \\
\text { (Camellia sinensis (L.) Kuntze) }\end{array}$} & \multirow{2}{*}{ In vitro } & SH-SY5Y & & $\bullet$ & {$[70]$} \\
\hline & & Cortical cultures & & - & {$[71]$} \\
\hline & \multirow{5}{*}{ In vivo } & Naïve animals & & • & {$[72-76]$} \\
\hline & & & $\bullet$ & & {$[77]$} \\
\hline & & Alzheimer's disease & & • & {$[79,80]$} \\
\hline & & DYRK1A transgenic mice & - & & {$[78]$} \\
\hline & & Obesity (high-fat diet) & & $\bullet$ & {$[81]$} \\
\hline \multirow{2}{*}{ Hypericum perforatum L. } & In vivo & Chronic stress & - & & {$[82,83]$} \\
\hline & Clinical & Depressed patient & & $\bullet$ & {$[84]$} \\
\hline \multirow{6}{*}{ Olive oil (Olea europaea L.) } & \multirow{4}{*}{ In vivo } & Naïve animals & & $\bullet$ & {$[87,88]$} \\
\hline & & & $\bullet$ & & {$[89]$} \\
\hline & & Alzheimer's disease & - & & [91] \\
\hline & & Prenatal stress & & • & {$[90]$} \\
\hline & \multirow{2}{*}{ Clinical } & Healthy subjects & & - & [92] \\
\hline & & Alcoholic patients & & - & [93] \\
\hline
\end{tabular}


TABLE 2: Continued.

\begin{tabular}{|c|c|c|c|c|c|}
\hline Botanicals & Type of studies & Models & mRNA & Protein & References \\
\hline \multirow{23}{*}{ Panax ginseng C.A. Meyer } & \multirow{5}{*}{ In vitro } & OECs & • & - & [94] \\
\hline & & $\mathrm{PC} 12$ & & - & [98] \\
\hline & & Rat brain slices & & $\bullet$ & [96] \\
\hline & & Rat hippocampal neurons & & - & [97] \\
\hline & & SCs & - & - & [95] \\
\hline & \multirow{18}{*}{ In vivo } & Naïve animals & & - & {$[114,121,122]$} \\
\hline & & & - & & [120] \\
\hline & & Acute stress & • & - & [108] \\
\hline & & & $\bullet$ & & {$[104]$} \\
\hline & & Alzheimer's disease & & $\bullet$ & [115] \\
\hline & & ADHD & & - & [61] \\
\hline & & Autoimmune encephalomyelitis & & $\bullet$ & {$[112]$} \\
\hline & & Cerebral ischemia-reperfusion & & $\bullet$ & {$[116,117]$} \\
\hline & & & $\bullet$ & $\bullet$ & {$[118]$} \\
\hline & & Chronic stress & & - & {$[99,101-103,107]$} \\
\hline & & & $\bullet$ & & [106] \\
\hline & & & $\bullet$ & $\bullet$ & {$[100]$} \\
\hline & & Corticosterone & $\bullet$ & $\bullet$ & [105] \\
\hline & & LPS-induced depression & • & & [119] \\
\hline & & Scopolamine & & $\bullet$ & [110] \\
\hline & & & $\bullet$ & & [109] \\
\hline & & SAMP8 & & $\bullet$ & [113] \\
\hline & & Streptozotocin & & $\bullet$ & [111] \\
\hline \multirow{4}{*}{ Perilla frutescens (L.) Britton } & \multirow{4}{*}{ In vivo } & Alzheimer's disease & & $\bullet$ & [127] \\
\hline & & Chronic stress & • & $\bullet$ & [123] \\
\hline & & Dietary restriction of ALA & & - & {$[124,125]$} \\
\hline & & Naïve animals & & $\bullet$ & [126] \\
\hline \multirow{2}{*}{ Rhodiola rosea $\mathrm{L}$. } & In vitro & Mesenchymal stem cells & $\bullet$ & $\bullet$ & [129] \\
\hline & In vivo & LPS-induced depression & & - & [130] \\
\hline \multirow{6}{*}{ Salvia miltiorrhiza Bunge } & \multirow{2}{*}{ In vitro } & BM-NSCs & & $\bullet$ & {$[132]$} \\
\hline & & SH-SY5Y & & $\bullet$ & [133] \\
\hline & \multirow{4}{*}{ In vivo } & Alzheimer's disease & & • & [134] \\
\hline & & & • & • & [135] \\
\hline & & Cerebral ischemia-reperfusion & & • & {$[136,137]$} \\
\hline & & Streptozotocin and cerebral ischemia-reperfusion & & $\bullet$ & {$[138]$} \\
\hline \multirow{4}{*}{ Vitis vinifera $\mathrm{L}$. } & \multirow{3}{*}{ In vivo } & Naïve animals & & $\bullet$ & {$[141,142]$} \\
\hline & & Acute stress & & $\bullet$ & [140] \\
\hline & & Oxidative stress & & $\bullet$ & [139] \\
\hline & Clinical & Healthy subjects & & $\bullet$ & [53] \\
\hline \multirow{2}{*}{ Withania somnifera (L.) Dunal } & \multirow{2}{*}{ In vivo } & Hypobaric hypoxia & & $\bullet$ & [145] \\
\hline & & Scopolamine & $\bullet$ & $\bullet$ & {$[144]$} \\
\hline
\end{tabular}

Studies which measured the BDNF mRNA or protein levels are indicated with the symbol "•".

although few papers did not report properly the type of solvent used.

In conclusion, considering the key role of the marker in different pathological conditions affecting the CNS, BDNF may represent an important tool to counteract these conditions, as demonstrated by the studies reported herein. Botanicals may be considered useful candidates to modulate in vivo BDNF. If clinical studies confirm this evidence, these natural products may be used for preventing CNS dysfunction or as a useful adjuvant to the pharmacological treatment. 


\section{Conflicts of Interest}

The authors declare no conflict of interest.

\section{Acknowledgments}

The publication costs are covered by "Piano di sviluppo di UNIMI-Linea 2, Azione A-Università degli Studi di Milano a giovani e talentuosi ricercatori (2016).”

\section{References}

[1] S. Lowel and W. Singer, "Selection of intrinsic horizontal connections in the visual cortex by correlated neuronal activity," Science, vol. 255, no. 5041, pp. 209-212, 1992.

[2] M. M. Poo, "Neurotrophins as synaptic modulators," Nature Review Neuroscience, vol. 2, no. 1, pp. 24-32, 2001.

[3] E. J. Huang and L. F. Reichardt, "Neurotrophins: roles in neuronal development and function," Annual Review of Neuroscience, vol. 24, no. 1, pp. 677-736, 2001.

[4] B. Lu, P. T. Pang, and N. H. Woo, "The yin and yang of neurotrophin action," Nature Review Neuroscience, vol. 6, no. 8, pp. 603-614, 2005.

[5] F. Calabrese, R. Molteni, G. Racagni, and M. A. Riva, "Neuronal plasticity: a link between stress and mood disorders," Psychoneuroendocrinology, vol. 34, Supplement 1, pp. S208-S216, 2009.

[6] R. B. Foltran and S. L. Diaz, "BDNF isoforms: a round trip ticket between neurogenesis and serotonin?," Journal of Neurochemistry, vol. 138, no. 2, pp. 204-221, 2016.

[7] T. Aid, A. Kazantseva, M. Piirsoo, K. Palm, and T. Timmusk, "Mouse and rat BDNF gene structure and expression revisited," Journal of Neuroscience Research, vol. 85, no. 3, pp. 525-535, 2007.

[8] P. Pruunsild, A. Kazantseva, T. Aid, K. Palm, and T. Timmusk, "Dissecting the human BDNF locus: bidirectional transcription, complex splicing, and multiple promoters," Genomics, vol. 90, no. 3, pp. 397-406, 2007.

[9] B. Lu, "BDNF and activity-dependent synaptic modulation," Learn Memory, vol. 10, no. 2, pp. 86-98, 2003.

[10] Z. L. Zhou, E. J. Hong, S. Cohen et al., "Brain-specific phosphorylation of MeCP2 regulates activity-dependent Bdnf transcription, dendritic growth, and spine maturation," Neuron, vol. 52, no. 2, pp. 255-269, 2006.

[11] R. Molteni, F. Calabrese, A. Cattaneo et al., "Acute stress responsiveness of the neurotrophin BDNF in the rat hippocampus is modulated by chronic treatment with the antidepressant duloxetine," Neuropsychopharmacology, vol. 34, no. 9, p. 2196, 2009.

[12] K. Martinowich, H. Manji, and B. Lu, "New insights into BDNF function in depression and anxiety," Nature Neuroscience, vol. 10, no. 9, pp. 1089-1093, 2007.

[13] B. Lu and K. Martinowich, "Cell biology of BDNF and its relevance to schizophrenia," Novartis Foundation Symposia, vol. 289, pp. 119-129, 2008.

[14] M. Mitre, A. Mariga, and M. V. Chao, "Neurotrophin signalling: novel insights into mechanisms and pathophysiology," Clinical Science, vol. 131, no. 1, pp. 13-23, 2017.

[15] A. H. Nagahara and M. H. Tuszynski, "Potential therapeutic uses of BDNF in neurological and psychiatric disorders,"
Nature Review Drug Discovery, vol. 10, no. 3, pp. 209-219, 2011.

[16] S. Yanev, "Neurotrophic and metabotrophic potential of nerve growth factor and brain-derived neurotrophic factor: linking cardiometabolic and neuropsychiatric diseases," World Journal of Pharmacology, vol. 2, no. 4, p. 92, 2013.

[17] B. Lu, G. H. Nagappan, X. M. Guan, P. J. Nathan, and P. Wren, "BDNF-based synaptic repair as a diseasemodifying strategy for neurodegenerative diseases," Nature Reviews Neuroscience, vol. 14, no. 6, pp. 401-416, 2013.

[18] Q. X. Ng, N. Venkatanarayanan, and C. Y. X. Ho, "Clinical use of Hypericum perforatum (St John' wort) in depression: a meta-analysis," Journal of Affective Disorders, vol. 210, pp. 211-221, 2017.

[19] S. Bent, A. Padula, D. H. Moore, M. Patterson, and W. Mehling, "Valerian for sleep: a systematic review and meta-analysis," Journal of General Internal Medicine, vol. 20, p. 90, 2005.

[20] J. Sarris, E. McIntyre, and D. A. Camfield, "Plant-based medicines for anxiety disorders, part 1: a review of preclinical studies," CNS Drugs, vol. 27, no. 3, pp. 207-219, 2013.

[21] P. M. Kidd, "A review of nutrients and botanicals in the integrative management of cognitive dysfunction," Alternative Medicine Review, vol. 4, no. 3, pp. 144-161, 1999.

[22] S. Aguiar and T. Borowski, "Neuropharmacological review of the nootropic herb Bacopa monnieri," Rejuvenation Research, vol. 16, no. 4, pp. 313-326, 2013.

[23] M. D. Pandareesh and T. Anand, "Neuromodulatory propensity of Bacopa monniera against scopolamine-induced cytotoxicity in PC12 cells via down-regulation of AChE and up-regulation of BDNF and muscarnic-1 receptor expression," Cellular and Molecular Neurobiology, vol. 33, no. 7, pp. 875-884, 2013.

[24] M. D. Pandareesh and T. Anand, "Neuroprotective and antiapoptotic propensity of Bacopa monniera extract against sodium nitroprusside induced activation of iNOS, heat shock proteins and apoptotic markers in PC12 cells," Neurochemical Research, vol. 39, no. 5, pp. 800-814, 2014.

[25] R. Banerjee, S. Hazra, A. K. Ghosh, and A. C. Mondal, "Chronic administration of Bacopa monniera increases BDNF protein and mRNA expressions: a study in chronic unpredictable stress induced animal model of depression," Psychiatry Investigation, vol. 11, no. 3, pp. 297-306, 2014.

[26] S. Hazra, S. Kumar, G. K. Saha, and A. C. Mondal, "Reversion of BDNF, Akt and CREB in hippocampus of chronic unpredictable stress induced rats: effects of phytochemical, Bacopa Monnieri," Psychiatry Investigation, vol. 14, no. 1, pp. 74-80, 2017.

[27] S. Kumar and A. C. Mondal, "Neuroprotective, neurotrophic and anti-oxidative role of Bacopa monnieri on CUS induced model of depression in rat," Neurochemical Research, vol. 41, no. 11, pp. 3083-3094, 2016.

[28] B. Czeh, E. Fuchs, O. Wiborg, and M. Simon, "Animal models of major depression and their clinical implications," Progress in Neuro-Psychopharmacology and Biological Psychiatry, vol. 64, pp. 293-310, 2016.

[29] X. T. Le, H. T. N. Pham, P. T. Do et al., “Bacopa monnieri ameliorates memory deficits in olfactory bulbectomized mice: possible involvement of glutamatergic and cholinergic systems," Neurochemical Research, vol. 38, no. 10, pp. 22012215, 2013. 
[30] M. D. Pandareesh, T. Anand, and F. Khanum, "Cognition enhancing and neuromodulatory propensity of Bacopa monniera extract against scopolamine induced cognitive impairments in rat hippocampus," Neurochemical Research, vol. 41, no. 5, pp. 985-999, 2016.

[31] A. Konar, A. Gautam, and M. K. Thakur, "Bacopa monniera (CDRI-08) upregulates the expression of neuronal and glial plasticity markers in the brain of scopolamine induced amnesic mice," Evidence-based Complementary and Alternative Medicine, vol. 2015, Article ID 837012, 9 pages, 2015.

[32] J. Preethi, H. K. Singh, and K. E. Rajan, "Possible involvement of standardized Bacopa monniera extract (CDRI-08) in epigenetic regulation of reelin and brain-derived neurotrophic factor to enhance memory," Frontiers in Pharmacology, vol. 7, 2016.

[33] J. Preethi, H. K. Singh, J. S. Venkataraman, and K. E. Rajan, "Standardised extract of Bacopa monniera (CDRI-08) improves contextual fear memory by differentially regulating the activity of histone acetylation and protein phosphatases (PP1 $\alpha, \mathrm{PP} 2 \mathrm{~A})$ in hippocampus," Cellular and Molecular Neurobiology, vol. 34, no. 4, pp. 577-589, 2014.

[34] C. Lao-Peregrin, J. J. Ballesteros, M. Fernandez et al., "Caffeine-mediated BDNF release regulates long-term synaptic plasticity through activation of IRS2 signaling," Addiction Biology, vol. 22, no. 6, pp. 1706-1718, 2016.

[35] A. Balkowiec and D. M. Katz, "Cellular mechanisms regulating activity-dependent release of native brain-derived neurotrophic factor from hippocampal neurons," The Journal of Neuroscience, vol. 22, no. 23, pp. 10399-10407, 2002.

[36] S. Connolly and T. J. Kingsbury, "Caffeine modulates CREBdependent gene expression in developing cortical neurons," Biochemical and Biophysical Research Communications, vol. 397, no. 2, pp. 152-156, 2010.

[37] K. M. Capiotti, F. P. Menezes, L. R. Nazario et al., "Early exposure to caffeine affects gene expression of adenosine receptors, DARPP-32 and BDNF without affecting sensibility and morphology of developing zebrafish (Danio rerio)," Neurotoxicology and Teratology, vol. 33, no. 6, pp. 680-685, 2011.

[38] A. P. Ardais, A. S. Rocha, M. F. Borges et al., "Caffeine exposure during rat brain development causes memory impairment in a sex selective manner that is offset by caffeine consumption throughout life," Behavioural Brain Research, vol. 303, pp. 76-84, 2016.

[39] S. Mioranzza, F. Nunes, D. M. Marques et al., "Prenatal caffeine intake differently affects synaptic proteins during fetal brain development," International Journal of Developmental Neuroscience, vol. 36, pp. 45-52, 2014.

[40] A. P. Ardais, M. F. Borges, A. S. Rocha, C. Sallaberry, R. A. Cunha, and L. O. Porciuncula, "Caffeine triggers behavioral and neurochemical alterations in adolescent rats," Neuroscience, vol. 270, pp. 27-39, 2014.

[41] C. Sallaberry, F. Nunes, M. S. Costa et al., "Chronic caffeine prevents changes in inhibitory avoidance memory and hippocampal BDNF immunocontent in middle-aged rats," Neuropharmacology, vol. 64, pp. 153-159, 2013.

[42] M. S. Costa, P. H. Botton, S. Mioranzza, D. O. Souza, and L. O. Porciuncula, "Caffeine prevents age-associated recognition memory decline and changes brain-derived neurotrophic factor and tirosine kinase receptor (TrkB) content in mice," Neuroscience, vol. 153, no. 4, pp. 1071-1078, 2008.

[43] M. S. Costa, P. H. Botton, S. Mioranzza et al., "Caffeine improves adult mice performance in the object recognition task and increases BDNF and TrkB independent on phospho-CREB immunocontent in the hippocampus," Neurochemistry International, vol. 53, no. 3-4, pp. 89-94, 2008.

[44] F. M. Ghoneim, H. A. Khalaf, A. Z. Elsamanoudy et al., "Protective effect of chronic caffeine intake on gene expression of brain derived neurotrophic factor signaling and the immunoreactivity of glial fibrillary acidic protein and Ki-67 in Alzheimer's disease," International Journal Clinical Experimental Pathology, vol. 8, no. 7, pp. 7710-7728, 2015.

[45] K. Han, N. Jia, J. Li, L. Yang, and L. Q. Min, "Chronic caffeine treatment reverses memory impairment and the expression of brain BNDF and TrkB in the PS1/APP double transgenic mouse model of Alzheimer's disease," Molecular Medicine Reports, vol. 8, no. 3, pp. 737-740, 2013.

[46] K. H. Alzoubi, M. Srivareerat, A. M. Aleisa, and K. A. Alkadhi, "Chronic caffeine treatment prevents stressinduced LTP impairment: the critical role of phosphorylated CaMKII and BDNF," Journal of Molecular Neuroscience, vol. 49, no. 1, pp. 11-20, 2013.

[47] G. A. Moy and E. C. McNay, "Caffeine prevents weight gain and cognitive impairment caused by a high-fat diet while elevating hippocampal BDNF," Physiology \& Behavior, vol. 109, pp. 69-74, 2013.

[48] J. S. Samkoff and C. H. M. Jacques, "A review of studies concerning effects of sleep deprivation and fatigue on residents' performance," Academic Medicine, vol. 66, no. 11, pp. 687693, 1991.

[49] S. Sahu, H. Kauser, K. Ray, K. Kishore, S. Kumar, and U. Panjwani, "Caffeine and modafinil promote adult neuronal cell proliferation during $48 \mathrm{~h}$ of total sleep deprivation in rat dentate gyrus," Experimental Neurology, vol. 248, pp. 470-481, 2013.

[50] I. A. Alhaider, A. M. Aleisa, T. T. Tran, and K. A. Alkadhi, "Caffeine prevents sleep loss-induced deficits in long-term potentiation and related signaling molecules in the dentate gyrus," European Journal of Neuroscience, vol. 31, no. 8, pp. 1368-1376, 2010.

[51] K. A. Alkadhi and I. A. Alhaider, "Caffeine and REM sleep deprivation: effect on basal levels of signaling molecules in area CA1," Molecular and Cellular Neuroscience, vol. 71, pp. 125-131, 2016.

[52] I. A. Alhaider, A. M. Aleisa, T. T. Tran, and K. A. Alkadhi, "Sleep deprivation prevents stimulation-induced increases of levels of P-CREB and BDNF: protection by caffeine," Molecular and Cellular Neuroscience, vol. 46, no. 4, pp. 742-751, 2011.

[53] T. Reyes-Izquierdo, B. Nemzer, C. Shu et al., "Modulatory effect of coffee fruit extract on plasma levels of brainderived neurotrophic factor in healthy subjects," British Journal of Nutrition, vol. 110, no. 03, pp. 420-425, 2013.

[54] M. R. Khazdair, M. H. Boskabady, M. Hosseini, R. Rezaee, and A. M. Tsatsakis, "The effects of Crocus sativus (saffron) and its constituents on nervous system: a review," Avicenna Journal of Phytomedicine, vol. 5, no. 5, pp. 376-391, 2015.

[55] F. V. Hassani, V. Naseri, B. M. Razavi, S. Mehri, K. Abnous, and $\mathrm{H}$. Hosseinzadeh, "Antidepressant effects of crocin and its effects on transcript and protein levels of CREB, BDNF, and VGF in rat hippocampus," Daru Journal of Pharmaceutical Sciences, vol. 22, no. 1, p. 16, 2014.

[56] T. Ghasemi, K. Abnous, F. Vahdati, S. Mehri, B. M. Razavi, and H. Hosseinzadeh, "Antidepressant effect of Crocus sativus aqueous extract and its effect on CREB, BDNF, and 
VGF transcript and protein levels in rat hippocampus," Drug Research, vol. 65, no. 07, pp. 337-343, 2015.

[57] ESCOP Monographs, Georg Thieme Verlag, Stuttgart, Germany, 2nd edition, 2009.

[58] F. Wu, H. Li, L. Zhao et al., "Protective effects of aqueous extract from Acanthopanax senticosus against corticosteroneinduced neurotoxicity in PC12 cells," Journal of Ethnopharmacology, vol. 148, no. 3, pp. 861-868, 2013.

[59] Y. Xu, C. Cui, C. Pang, Y. Christen, and Y. Luo, "Restoration of impaired phosphorylation of cyclic AMP response element-binding protein (CREB) by EGb 761 and its constituents in A $\beta$-expressing neuroblastoma cells," European Journal of Neuroscience, vol. 26, no. 10, pp. 2931-2939, 2007.

[60] Y. Hou, M. A. Aboukhatwa, D. L. Lei, K. Manaye, I. Khan, and Y. Luo, "Anti-depressant natural flavonols modulate BDNF and beta amyloid in neurons and hippocampus of double TgAD mice," Neuropharmacology, vol. 58, no. 6, pp. 911-920, 2010.

[61] Y. Nam, E. J. Shin, S. W. Shin et al., "YY162 prevents ADHD-like behavioral side effects and cytotoxicity induced by Aroclor1254 via interactive signaling between antioxidant potential, BDNF/TrkB, DAT and NET," Food and Chemical Toxicology, vol. 65, pp. 280-292, 2014.

[62] Z. Zhang, D. Peng, H. Zhu, and X. Wang, "Experimental evidence of Ginkgo biloba extract EGB as a neuroprotective agent in ischemia stroke rats," Brain Research Bulletin, vol. 87, no. 2-3, pp. 193-198, 2012.

[63] M. Belviranli and N. Okudan, "The effects of Ginkgo biloba extract on cognitive functions in aged female rats: the role of oxidative stress and brain-derived neurotrophic factor," Behavioral Brain Research, vol. 278, pp. 453-461, 2015.

[64] Y. Zhao, Y. Zhang, and F. Pan, "The effects of EGb761 on lipopolysaccharide-induced depressive-like behaviour in C57BL/6J mice," Central European Journal of Immunology, vol. 1, no. 1, pp. 11-17, 2015.

[65] J. Shi, Y. L. Tan, Z. R. Wang et al., "Ginkgo biloba and vitamin E ameliorate haloperidol-induced vacuous chewingmovement and brain-derived neurotrophic factor expression in a rat tardive dyskinesia model," Pharmacology Biochemistry and Behavior, vol. 148, pp. 53-58, 2016.

[66] X. S. Qin, K. H. Jin, B. K. Ding, S. F. Xie, and H. Ma, “Effects of extract of Ginkgo biloba with venlafaxine on brain injury in a rat model of depression," Chinese Medical Journal, vol. 118, no. 5, pp. 391-397, 2005.

[67] F. Tchantchou, P. N. Lacor, Z. Cao et al., "Stimulation of neurogenesis and synaptogenesis by bilobalide and quercetin via common final pathway in hippocampal neurons," Journal of Alzheimer's Disease, vol. 18, no. 4, pp. 787-798, 2009.

[68] X. Y. Zhang, W. F. Zhang, D. F. Zhou et al., "Brain-derived neurotrophic factor levels and its Val66Met gene polymorphism predict tardive dyskinesia treatment response to Ginkgo biloba," Biological Psychiatry, vol. 72 , no. 8, pp. 700-706, 2012.

[69] C. Di Lorenzo, M. Dell'Agli, E. Sangiovanni et al., "Correlation between catechin content and NF- $\kappa$ B inhibition by infusions of green and black tea," Plant Foods Human Nutrition, vol. 68, no. 2, pp. 149-154, 2013.

[70] H. S. Cho, S. Kim, S. Y. Lee, J. A. Park, S. J. Kim, and H. S. Chun, "Protective effect of the green tea component,
L-theanine on environmental toxins-induced neuronal cell death," Neurotoxicology, vol. 29, no. 4, pp. 656-662, 2008.

[71] S. Nath, M. Bachani, D. Harshavardhana, and J. P. Steiner, "Catechins protect neurons against mitochondrial toxins and HIV proteins via activation of the BDNF pathway," Journal of Neurovirology, vol. 18, no. 6, pp. 445-455, 2012.

[72] C. Wakabayashi, T. Numakawa, M. Ninomiya, S. Chiba, and H. Kunugi, "Behavioral and molecular evidence for psychotropic effects in L-theanine," Psychopharmacology, vol. 219, no. 4, pp. 1099-1109, 2012.

[73] T. P. Stringer, D. Guerrieri, C. Vivar, and H. van Praag, "Plantderived flavanol (-)epicatechin mitigates anxiety in association with elevated hippocampal monoamine and BDNF levels, but does not influence pattern separation in mice," Translational Psychiatry, vol. 5, no. 1, article e493, 2015.

[74] A. Takeda, K. Sakamoto, H. Tamano et al., "Facilitated neurogenesis in the developing hippocampus after intake of theanine, an amino acid in tea leaves, and object recognition memory," Cellular and Molecular Neurobiology, vol. 31, no. 7, pp. 1079-1088, 2011.

[75] M. Assuncao, M. J. Santos-Marques, F. Carvalho, and J. P. Andrade, "Green tea averts age-dependent decline of hippocampal signaling systems related to antioxidant defenses and survival," Free Radical Biology \& Medicine, vol. 48, no. 6, pp. 831-838, 2010.

[76] Q. Li, H. F. Zhao, Z. F. Zhang et al., "Long-term administration of green tea catechins prevents age-related spatial learning and memory decline in C57BL/6 J mice by regulating hippocampal cyclic amp-response element binding protein signaling cascade," Neuroscience, vol. 159, no. 4, pp. 12081215, 2009.

[77] T. E. Gibbons, B. D. Pence, G. Petr et al., "Voluntary wheel running, but not a diet containing (-)-epigallocatechin-3gallate and $\beta$-alanine, improves learning, memory and hippocampal neurogenesis in aged mice," Behavioural Brain Research, vol. 272, pp. 131-140, 2014.

[78] F. Guedj, C. Sebrie, I. Rivals et al., "Green tea polyphenols rescue of brain defects induced by overexpression of DYRK1A," PLoS One, vol. 4, no. 2, 2009.

[79] Q. Li, H. F. Zhao, Z. F. Zhang et al., "Long-term green tea catechin administration prevents spatial learning and memory impairment in senescence-accelerated mouse prone- 8 mice by decreasing a $\beta_{1-42}$ oligomers and upregulating synaptic plasticity-related proteins in the hippocampus," Neuroscience, vol. 163, no. 3, pp. 741-749, 2009.

[80] Z. Y. Zhang, H. Wu, and H. C. Huang, "Epicatechin plus treadmill exercise are neuroprotective against moderatestage amyloid precursor protein/presenilin 1 mice," Pharmacognosy Magazine, vol. 12, no. 46, pp. 139-146, 2016.

[81] Y. H. Yu, Y. Z. Wu, A. Szabo et al., "Teasaponin improves leptin sensitivity in the prefrontal cortex of obese mice," Molecular Nutrition \& Food Research, vol. 59, no. 12, pp. 2371-2382, 2015.

[82] S. S. Patel, N. Mahindroo, and M. Udayabanu, "Urtica dioica leaves modulates hippocampal smoothened-glioma associated oncogene-1 pathway and cognitive dysfunction in chronically stressed mice," Biomedicine \& Pharmacotherapy, vol. 83, pp. 676-686, 2016.

[83] V. Butterweck, H. Winterhoff, and M. Herkenham, “St John's wort, hypericin, and imipramine: a comparative analysis of mRNA levels in brain areas involved in HPA axis control following short-term and long-term administration in normal 
and stressed rats," Molecular Psychiatry, vol. 6, no. 5, pp. 547$564,2001$.

[84] M. L. Molendijk, B. A. A. Bus, P. Spinhoven et al., "Serum levels of brain-derived neurotrophic factor in major depressive disorder: state-trait issues, clinical features and pharmacological treatment," Molecular Psychiatry, vol. 16, no. 11, pp. 1088-1095, 2011.

[85] M. Dell'agli and E. Bosisio, "Minor polar compounds of olive oil: composition, factors of variability and bioactivity," Studies in Natural Products Chemistry, vol. 27, pp. 697-734, 2002.

[86] E. Muto, M. Dell'Agli, E. Sangiovanni et al., "Olive oil phenolic extract regulates interleukin-8 expression by transcriptional and posttranscriptional mechanisms in Caco-2 cells," Molecular Nutrition \& Food Research, vol. 59, no. 6, pp. 1217-1221, 2015.

[87] S. De Nicolo, L. Tarani, M. Ceccanti et al., "Effects of olive polyphenols administration on nerve growth factor and brain-derived neurotrophic factor in the mouse brain," Nutrition, vol. 29, no. 4, pp. 681-687, 2013.

[88] V. Carito, A. Venditti, A. Bianco et al., "Effects of olive leaf polyphenols on male mouse brain NGF, BDNF and their receptors TrkA, TrkB and p75," Natural Product Research, vol. 28, no. 22, pp. 1970-1984, 2014.

[89] C. S. Pase, A. M. Teixeira, K. Roversi et al., "Olive oilenriched diet reduces brain oxidative damages and ameliorates neurotrophic factor gene expression in different life stages of rats," The Journal of Nutritional Biochemistry, vol. 26, no. 11, pp. 1200-1207, 2015.

[90] A. Zheng, H. Li, K. Cao et al., "Maternal hydroxytyrosol administration improves neurogenesis and cognitive function in prenatally stressed offspring," The Journal of Nutritional Biochemistry, vol. 26, no. 2, pp. 190-199, 2015.

[91] M. Arunsundar, T. S. Shanmugarajan, and V. Ravichandran, "3,4-Dihydroxyphenylethanol attenuates spatio-cognitive deficits in an Alzheimer's disease mouse model: modulation of the molecular signals in neuronal survival-apoptotic programs," Neurotoxicity Research, vol. 27, no. 2, pp. 143-155, 2015.

[92] A. Sanchez-Villegas, C. Galbete, M. A. Martinez-Gonzalez et al., "The effect of the Mediterranean diet on plasma brain-derived neurotrophic factor (BDNF) levels: the PREDIMED-NAVARRA randomized trial," Nutritional Neuroscience, vol. 14, no. 5, pp. 195-201, 2011.

[93] M. Ceccanti, V. Carito, M. Vitali et al., "Serum BDNF and NGF modulation by olive polyphenols in alcoholics during withdrawal," Journal of Alcoholism \& Drug Dependence, vol. 3, no. 4, pp. 214-219, 2015.

[94] Z. F. Lu, Y. X. Shen, P. Zhang et al., "Ginsenoside Rg1 promotes proliferation and neurotrophin expression of olfactory ensheathing cells," Journal of Asian Natural Products Research, vol. 12, no. 4, pp. 265-272, 2010.

[95] J. Ma, J. Liu, Q. Wang, H. Yu, Y. Chen, and L. Xiang, “The beneficial effect of ginsenoside $\operatorname{Rg} 1$ on Schwann cells subjected to hydrogen peroxide induced oxidative injury," International Journal of Biological Sciences, vol. 9, no. 6, pp. 624-636, 2013.

[96] X. Li, M. Li, Y. Li, Q. Quan, and J. Wang, "Cellular and molecular mechanisms underlying the action of ginsenoside Rg1 against Alzheimer's disease," Neural Regeneration Research, vol. 7, no. 36, pp. 2860-2866, 2012.
[97] J. Y. Han, S. Y. Ahn, E. H. Oh et al., "Red ginseng extract attenuates kainate-induced excitotoxicity by antioxidative effects," Evidence-based Complementary and Alternative Medicine, vol. 2012, Article ID 479016, 10 pages, 2012.

[98] X. Y. Liu, X. Y. Zhou, J. C. Hou et al., “Ginsenoside Rd promotes neurogenesis in rat brain after transient focal cerebral ischemia via activation of PI3K/Akt pathway," Acta Pharmacologica Sinica, vol. 36, no. 4, pp. 421-428, 2015.

[99] H. Dang, Y. Chen, X. Liu et al., "Antidepressant effects of ginseng total saponins in the forced swimming test and chronic mild stress models of depression," Progress in NeuroPsychopharmacology and Biological Psychiatry, vol. 33, no. 8, pp. 1417-1424, 2009.

[100] B. Jiang, Z. Xiong, J. Yang et al., “Antidepressant-like effects of ginsenoside Rg1 are due to activation of the BDNF signalling pathway and neurogenesis in the hippocampus," British Journal of Pharmacology, vol. 166, no. 6, pp. 1872-1887, 2012.

[101] J. Cui, L. Jiang, and H. Xiang, "Ginsenoside Rb3 exerts antidepressant-like effects in several animal models," Journal of Psychopharmacology, vol. 26, no. 5, pp. 697-713, 2012.

[102] X. Zhu, R. Gao, Z. Liu et al., "Ginsenoside Rg1 reverses stressinduced depression-like behaviours and brain-derived neurotrophic factor expression within the prefrontal cortex," European Journal of Neuroscience, vol. 44, no. 2, pp. 18781885, 2016.

[103] Z. Liu, Y. Qi, Z. Cheng, X. Zhu, C. Fan, and S. Y. Yu, "The effects of ginsenoside $\mathrm{Rg} 1$ on chronic stress induced depression-like behaviors, BDNF expression and the phosphorylation of PKA and CREB in rats," Neuroscience, vol. 322, pp. 358-369, 2016.

[104] B. Lee, B. Sur, S. G. Cho et al., "Ginsenoside Rb1 rescues anxiety-like responses in a rat model of post-traumatic stress disorder," Journal of Natural Medicines, vol. 70, no. 2, pp. 133-144, 2016.

[105] L. Chen, J. Dai, Z. Wang, H. Zhang, Y. Huang, and Y. Zhao, "Ginseng total saponins reverse corticosterone-induced changes in depression-like behavior and hippocampal plasticity-related proteins by interfering with GSK-3 $\beta$-CREB signaling pathway," Evidence-based Complementary and Alternative Medicine, vol. 2014, Article ID 506735, 11 pages, 2014.

[106] B. Lee, I. Shim, H. Lee, and D. H. Hahm, "Effect of ginsenoside Re on depression- and anxiety-like behaviors and cognition memory deficit induced by repeated immobilization in rats," Journal of Microbiology and Biotechnology, vol. 22, no. 5, pp. 708-720, 2012.

[107] W. Kezhu, X. Pan, L. Cong et al., "Effects of ginsenoside Rg1 on learning and memory in a reward-directed instrumental conditioning task in chronic restraint stressed rats," Phytotherapy Research, vol. 31, no. 1, pp. 81-89, 2016.

[108] M. Kim, S. O. Kim, M. Lee et al., "Effects of ginsenoside Rb1 on the stress-induced changes of BDNF and HSP70 expression in rat hippocampus," Environmental Toxicology and Pharmacology, vol. 38, no. 1, pp. 257-262, 2014.

[109] B. Lee, J. Park, S. Kwon et al., "Effect of wild ginseng on scopolamine-induced acetylcholine depletion in the rat hippocampus," Journal of Pharmacy and Pharmacology, vol. 62 , no. 2, pp. 263-271, 2010.

[110] E. J. Kim, I. H. Jung, T. K. Van Le, J. J. Jeong, N. J. Kim, and D. H. Kim, "Ginsenosides Rg5 and Rh3 protect scopolamine- 
induced memory deficits in mice," Journal of Ethnopharmacology, vol. 146, no. 1, pp. 294-299, 2013.

[111] S. Chu, J. Gu, L. Feng et al., "Ginsenoside Rg5 improves cognitive dysfunction and beta-amyloid deposition in STZ-induced memory impaired rats via attenuating neuroinflammatory responses," International Immunopharmacology, vol. 19, no. 2, pp. 317-326, 2014.

[112] D. Zhu, M. Liu, Y. Yang et al., "Ginsenoside Rd ameliorates experimental autoimmune encephalomyelitis in C57BL/6 mice," Journal of Neuroscience Research, vol. 92, no. 9, pp. 1217-1226, 2014.

[113] Y. Q. Shi, T. W. Huang, L. M. Chen et al., "Ginsenoside Rg1 attenuates amyloid- $\beta$ content, regulates PKA/CREB activity, and improves cognitive performance in SAMP8 mice," Journal of Alzheimer's Disease, vol. 19, no. 3, pp. 977-989, 2010.

[114] G. Zhu, Y. Wang, J. Li, and J. Wang, "Chronic treatment with ginsenoside Rg1 promotes memory and hippocampal longterm potentiation in middle-aged mice," Neuroscience, vol. 292, pp. 81-89, 2015.

[115] F. Li, X. Wu, J. Li, and Q. Niu, "Ginsenoside Rg1 ameliorates hippocampal long-term potentiation and memory in an Alzheimer's disease model," Molecular Medicine Reports, vol. 13, no. 6, pp. 4904-4910, 2016.

[116] X. Q. Gao, C. X. Yang, G. J. Chen et al., "Ginsenoside Rb1 regulates the expressions of brain-derived neurotrophic factor and caspase- 3 and induces neurogenesis in rats with experimental cerebral ischemia," Journal of Ethnopharmacology, vol. 132, no. 2, pp. 393-399, 2010.

[117] Z. Jiang, Y. Wang, X. Zhang et al., "Preventive and therapeutic effects of ginsenoside Rb1 for neural injury during cerebral infarction in rats," The American Journal of Chinese Medicine, vol. 41, no. 02, pp. 341-352, 2013.

[118] Q. Wan, X. Ma, Z. J. Zhang et al., "Ginsenoside reduces cognitive impairment during chronic cerebral hypoperfusion through brain-derived neurotrophic factor regulated by epigenetic modulation," Molecular Neurobiology, vol. 54, no. 4, pp. 2889-2900, 2016.

[119] X. Zheng, Y. Liang, A. Kang et al., "Peripheral immunomodulation with ginsenoside Rg1 ameliorates neuroinflammationinduced behavioral deficits in rats," Neuroscience, vol. 256, pp. 210-222, 2014.

[120] K. N. Salim, B. S. McEwen, and H. M. Chao, "Ginsenoside $\mathrm{Rb} 1$ regulates ChAT, NGF and trkA mRNA expression in the rat brain," Molecular Brain Research, vol. 47, no. 1-2, pp. 177-182, 1997.

[121] J. Hou, J. Xue, M. Lee, J. Yu, and C. Sung, "Long-term administration of ginsenoside Rh1 enhances learning and memory by promoting cell survival in the mouse hippocampus," International Journal of Molecular Medicine, vol. 33, no. 1, pp. 234-240, 2014.

[122] S. Kim, M. S. Kim, K. Park et al., "Hippocampus-dependent cognitive enhancement induced by systemic gintonin administration," Journal of Ginseng Research, vol. 40, no. 1, pp. 5561, 2016.

[123] L. T. Yi, J. Li, D. Geng et al., "Essential oil of Perilla frutescensinduced change in hippocampal expression of brain-derived neurotrophic factor in chronic unpredictable mild stress in mice," Journal of Ethnopharmacology, vol. 147, no. 1, pp. 245-253, 2013.

[124] D. Miyazawa, Y. Yasui, K. Yamada, N. Ohara, and H. Okuyama, "Biochemical responses to dietary $\alpha$-linolenic acid restriction proceed differently among brain regions in mice," Biomedical Research, vol. 32, no. 4, pp. 237-245, 2011.

[125] D. Miyazawa, Y. Yasui, K. Yamada, N. Ohara, and H. Okuyama, "Regional differences of the mouse brain in response to an $\alpha$-linolenic acid-restricted diet: neurotrophin content and protein kinase activity," Life Sciences, vol. 87, no. 15-16, pp. 490-494, 2010.

[126] H. C. Lee, H. K. Ko, B. E. Huang, Y. H. Chu, and S. Y. Huang, "Antidepressant-like effects of Perilla frutescens seed oil during a forced swimming test," Food \& Function, vol. 5, no. 5, pp. 990-996, 2014.

[127] A. Y. Lee, J. M. Choi, J. Lee, M. H. Lee, S. Lee, and E. J. Cho, "Effects of vegetable oils with different fatty acid compositions on cognition and memory ability in $\mathrm{A} \beta_{25-35}$-induced Alzheimer's disease mouse model," Journal of Medicinal Food, vol. 19, no. 10, pp. 912-921, 2016.

[128] A. Panossian, G. Wikman, and J. Sarris, "Rosenroot (Rhodiola rosea): traditional use, chemical composition, pharmacology and clinical efficacy," Phytomedicine, vol. 17, no. 7, pp. 481-493, 2010.

[129] H. B. Zhao, H. Ma, X. Q. Ha et al., "Salidroside induces rat mesenchymal stem cells to differentiate into dopaminergic neurons," Cell Biology International, vol. 38, no. 4, pp. 462471, 2014.

[130] L. P. Zhu, T. T. Wei, J. Gao et al., "Salidroside attenuates lipopolysaccharide (LPS) induced serum cytokines and depressive-like behavior in mice," Neuroscience Letters, vol. 606, pp. 1-6, 2015.

[131] L. Bonaccini, A. Karioti, M. C. Bergonzi, and A. R. Bilia, "Effects of Salvia miltiorrhiza on CNS neuronal injury and degeneration: a plausible complementary role of Tanshinones and Depsides," Planta Medica, vol. 81, no. 12-13, pp. 1003-1016, 2015.

[132] N. Zhang, T. Kang, Y. Xia et al., "Effects of salvianolic acid B on survival, self-renewal and neuronal differentiation of bone marrow derived neural stem cells," European Journal of Pharmacology, vol. 697, no. 1-3, pp. 32-39, 2012.

[133] Y. Wang, J. Zhang, M. Han et al., "SMND-309 promotes neuron survival through the activation of the PI3K/Akt/CREBsignalling pathway," Pharmaceutical Biology, vol. 54, no. 10, pp. 1982-1990, 2016.

[134] Y. W. Lee, D. H. Kim, S. J. Jeon et al., "Neuroprotective effects of salvianolic acid $\mathrm{B}$ on an $\mathrm{A} \beta_{25-35}$ peptide-induced mouse model of Alzheimer's disease," European Journal of Pharmacology, vol. 704, no. 1-3, pp. 70-77, 2013.

[135] Y. Teng, M. Q. Zhang, W. Wang et al., "Compound danshen tablet ameliorated a $\beta_{25-35}$-induced spatial memory impairment in mice via rescuing imbalance between cytokines and neurotrophins," BMC Complementary and Alternative Medicine, vol. 14, no. 1, p. 23, 2014.

[136] J. H. Park, O. K. Park, B. Yan et al., "Neuroprotection via maintenance or increase of antioxidants and neurotrophic factors in ischemic gerbil hippocampus treated with tanshinone I," Chinese Medical Journal, vol. 127, no. 19, pp. 3396-3405, 2014.

[137] M. Y. Chien, C. H. Chuang, C. M. Chern et al., "Salvianolic acid A alleviates ischemic brain injury through the inhibition of inflammation and apoptosis and the promotion of neurogenesis in mice," Free Radical Biology \& Medicine, vol. 99, pp. 508-519, 2016. 
[138] Q. He, S. Wang, X. Liu et al., "Salvianolate lyophilized injection promotes post-stroke functional recovery via the activation of VEGF and BDNF-TrkB-CREB signaling pathway," International Journal of Clinical Experimental Medicine, vol. 8, no. 1, pp. 108-122, 2015.

[139] F. Allam, A. T. Dao, G. Chugh et al., "Grape powder supplementation prevents oxidative stress-induced anxiety-like behavior, memory impairment, and high blood pressure in rats," The Journal of Nutrition, vol. 143, no. 6, pp. 835-842, 2013.

[140] N. Solanki, I. Alkadhi, F. Atrooz, G. Patki, and S. Salim, "Grape powder prevents cognitive, behavioral, and biochemical impairments in a rat model of posttraumatic stress disorder," Nutrition Research, vol. 35, no. 1, pp. 65-75, 2015.

[141] M. Fiore, G. Laviola, L. Aloe, V. di Fausto, R. Mancinelli, and M. Ceccanti, "Early exposure to ethanol but not red wine at the same alcohol concentration induces behavioral and brain neurotrophin alterations in young and adult mice," Neurotoxicology, vol. 30, no. 1, pp. 59-71, 2009.

[142] M. Ceccanti, R. Mancinelli, P. Tirassa et al., "Early exposure to ethanol or red wine and long-lasting effects in aged mice. A study on nerve growth factor, brain-derived neurotrophic factor, hepatocyte growth factor, and vascular endothelial growth factor," Neurobiology of Aging, vol. 33, no. 2, pp. 359-367, 2012.

[143] N. J. Dar, A. Hamid, and M. Ahmad, "Pharmacologic overview of Withania somnifera, the Indian ginseng," Cellular and Molecular Life Sciences, vol. 72, no. 23, pp. 4445-4460, 2015.

[144] A. Konar, N. Shah, R. Singh et al., "Protective role of Ashwagandha leaf extract and its component withanone on scopolamine-induced changes in the brain and brainderived cells," PLoS One, vol. 6, no. 11, article e27265, 2011.

[145] I. Baitharu, V. Jain, S. N. Deep et al., "Withania somnifera root extract ameliorates hypobaric hypoxia induced memory impairment in rats," Journal of Ethnopharmacology, vol. 145, no. 2, pp. 431-441, 2013. 

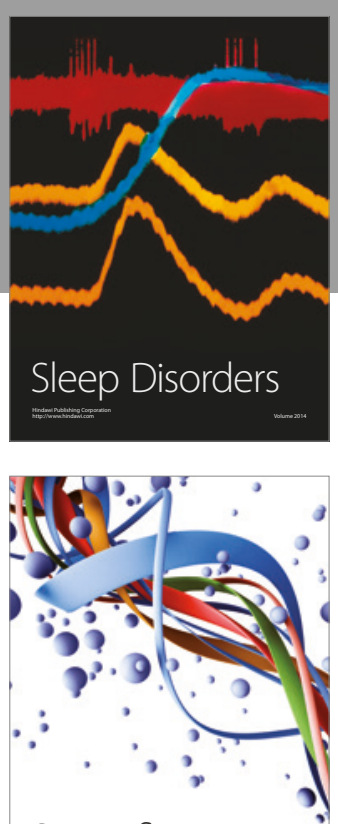

Scientifica
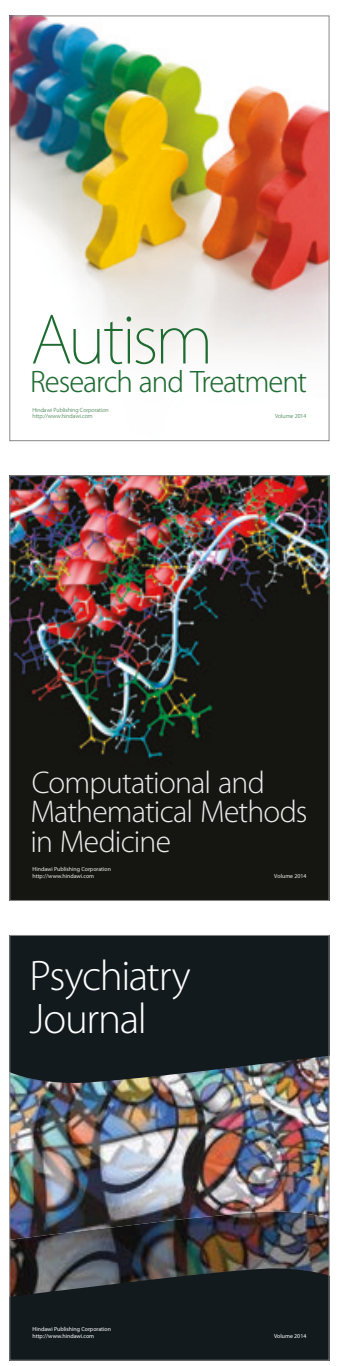
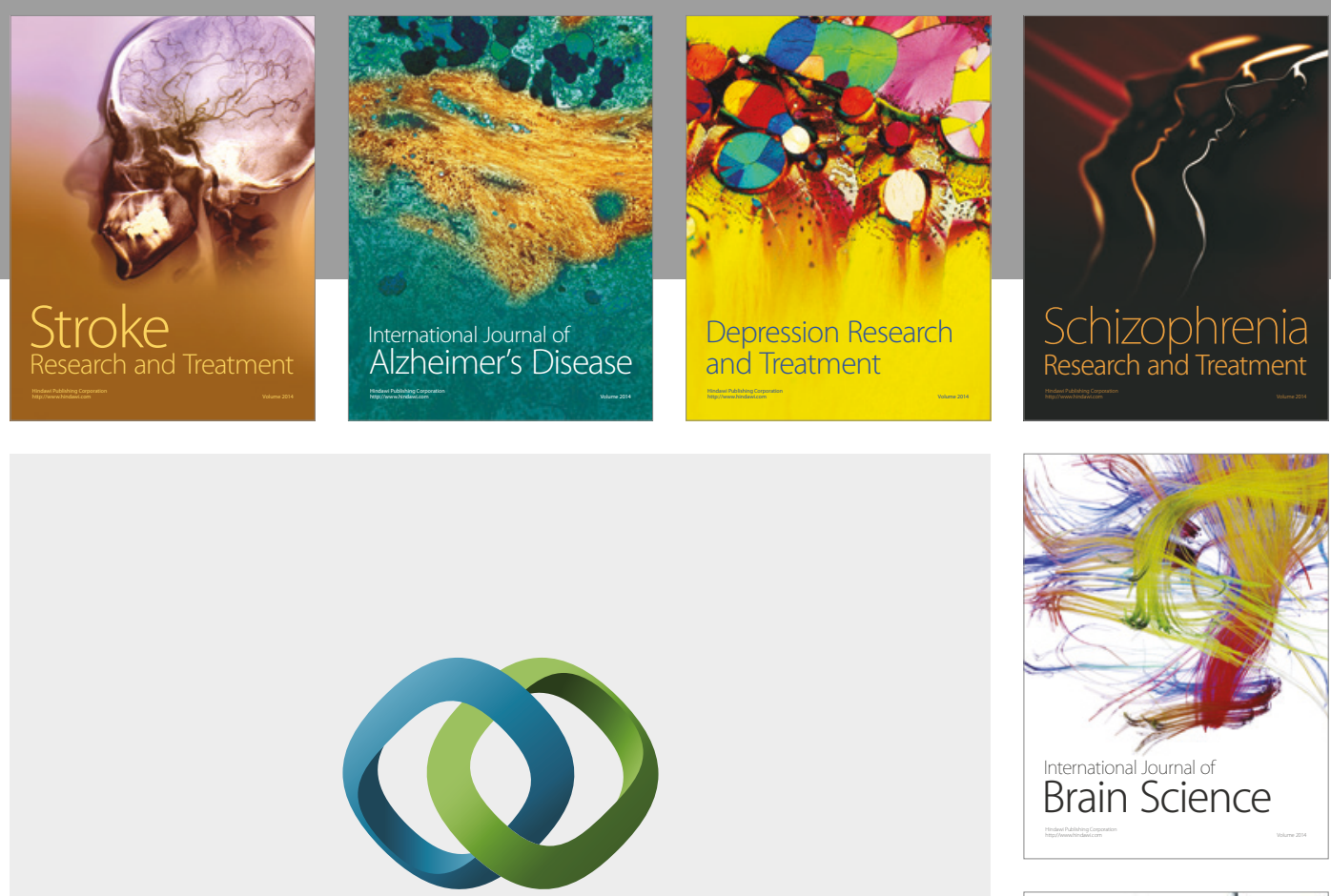

\section{Hindawi}

Submit your manuscripts at

https://www.hindawi.com
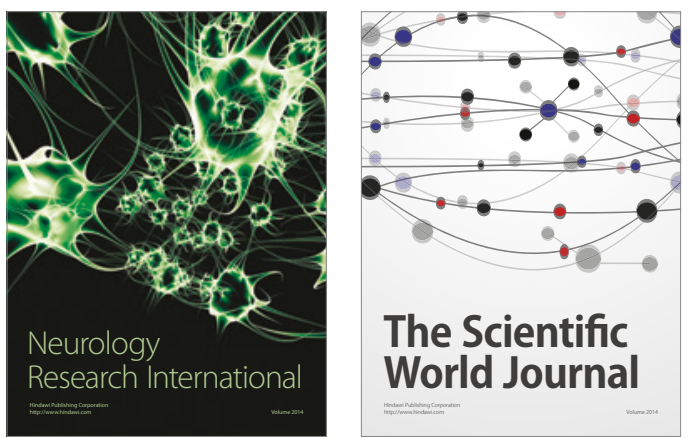

The Scientific World Journal

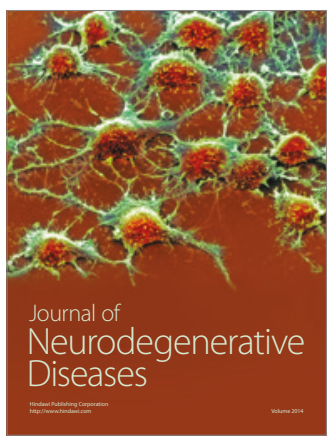

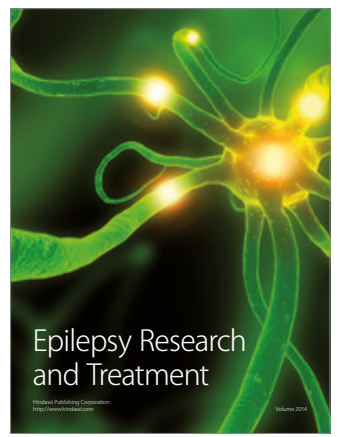

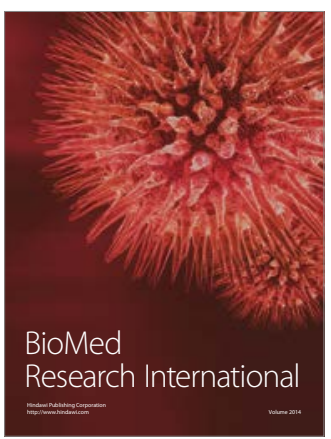

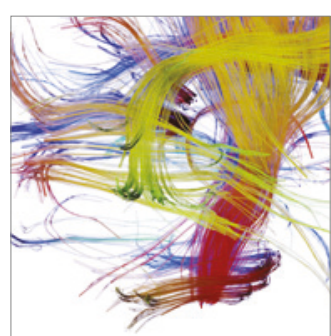

Brain Science

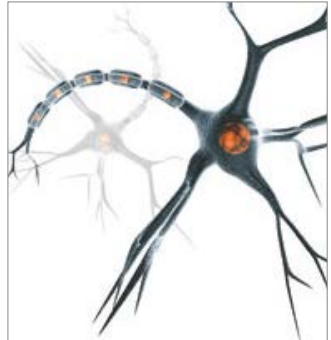

Neural Plasticity
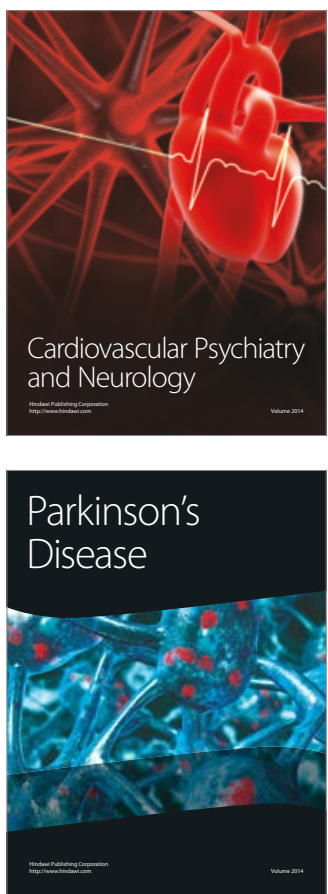